\title{
Decoding commensal-host communication through genetic engineering of Staphylococcus
} epidermidis

\author{
Y. Erin Chen ${ }^{1,2}$, Nicolas Bouladoux ${ }^{3,4}$, Charlotte Hurabielle ${ }^{3,5}$, Aiden M. Mattke ${ }^{3}$, Yasmine Belkaid $^{3,4^{*}}$, \\ Michael A. Fischbach ${ }^{1, *}$
}

1Department of Bioengineering and ChEM-H, Stanford University, Stanford, CA 94305, USA.

2Dermatology Service, San Francisco Veteran Affairs Medical Center.

${ }_{3}^{3}$ Metaorganism Immunity Section, Laboratory of Immune System Biology, National Institute of Allergy and Infectious Diseases, National Institutes of Health, Bethesda, MD 20892, USA.

${ }^{4}$ NIAID Microbiome Program, Bethesda, MD 20892, USA.

5Inserm U976, Hôpital Saint Louis, Université Paris Diderot, Paris, France

3

4

5


SUMMARY

Commensal skin bacteria elicit potent, antigen-specific immune responses in the skin without barrier breach or visible inflammation. While microbial modulation of immune homeostasis has profound consequences for epithelial health and inflammatory skin diseases, the mechanisms of microbe-immune crosstalk in the skin are largely unknown. A key barrier to mechanistic work has been genetic intractability of one of the most prevalent skin colonists, Staphylococcus epidermidis (S. epidermidis). Here, we develop a novel method to create a library of mutants with defined cell envelope alterations in primary human S. epidermidis isolates. By colonizing mice with these mutants, we uncover bacterial molecules involved in the induction of defined immune signatures. Notably, we show that under conditions of physiologic colonization, S. epidermidis cell envelope glycolipids are sensed by C-type lectin receptors, likely in non-myeloid cells, in conjunction with Toll-like receptors. This combinatorial signaling determines the quality of $\mathrm{T}$ cell responses and results in the potential for greater specificity toward commensal microbiota than previously appreciated. Additionally, the microbial molecules required for the colonization-induced immune response are dispensable for $\mathbf{T}$ cells responses in a model of $S$. epidermidis infection, but differentially modulate innate inflammatory responses. Thus, the same microbe uses distinct sets of molecules to signal to the immune system commensal versus pathogenic behavior, and differential sensing of these microbial signals depends on host context.

\section{Keywords}

skin microbiome, Staphylococcus epidermidis, microbiology, immunology, teichoic acids, innate immune receptors 


\section{MAIN TEXT}

Commensal skin bacteria elicit potent, taxon-specific immune responses in the skin under conditions of normal colonization, without breach of the skin barrier (Naik et al., 2012; Ridaura et al., 2018). These microbiota-derived stimuli play a critical role in reactivity to inflammatory triggers (Ridaura et al., 2018; Scharschmidt et al., 2015, 2017), pathogen resistance (Naik et al., 2015), and wound healing (Harrison et al., 2019; Linehan et al., 2018; Williams et al., 2019). Despite their fundamental importance to skin biology, the mechanisms by which commensals and immune cells interact are poorly understood. The unique features of commensal sensing include: (1) presumptive sampling of whole microbial cells (or microbial products) through an intact epithelial barrier, (2) a low biomass of highly diverse microbial signals relative to infection, and (3) the lack of inflammatory signals that would result from epithelial injury. These features make sensing of commensal organisms and orchestrating a balanced, homeostatic immune response a unique process, distinct from the sensing of an invading pathogen. Defining the mechanisms of microbe-immune cell communication would allow us to understand the molecular underpinnings of immunity at the skin barrier and identify new targets for modulating immune responses in the context of skin disease.

Most efforts to study commensal-host interactions have focused on the host genes and cell populations involved, rather than the microbial molecules responsible for driving host responses. In the case of $S$. epidermidis, colonization provokes a non-inflammatory $\mathrm{CD}^{+}$and $\mathrm{CD} 8^{+} \mathrm{T}$ cell response with wound healing and pathogen resistance properties in both mice and non-human primates (Linehan et al., 2018; Naik et al., 2012, 2015). In particular, the CD8+ T cell response is characterized by the co-expression type 17 and type 2 programs, allowing these cells to promote both antimicrobial defense and wound repair (Harrison et al., 2019; Linehan et al., 2018; Naik et al., 2012, 2015). S. epidermidis-induced CD8+ T cells are specific for $S$. epidermidis $\mathrm{N}$-formylated peptide antigens that are presented by nonclassical $\mathrm{MHC}$ I molecule H2-M3, a process that depends upon dermal dendritic cells (Linehan et al., 2018; Naik et al., 2015). Although the class of cognate peptide antigens is now known for CD8+ T cells, the S. epidermidis molecules that direct epithelial and antigen-presenting cell signaling in the initial stages of encounter, ultimately directing the downstream $\mathrm{CD}^{+}$and $\mathrm{CD}^{+} \mathrm{T}$ cell response, are undefined. More generally, the mechanisms and molecular partners involved in host-microbiota interaction remain poorly understood.

A major barrier to mechanistic understanding of this $S$. epidermidis-immune interaction has been the genetic intractability of $S$. epidermidis, a limitation common to most members of the human microbiota. S. epidermidis colonizes the skin of every human (Grice et al., 2009), and in the context of barrier breach (for example, device implantation) or immunocompromise, it is a frequent pathogen (Otto, 2009). However, only a few reports exist of methods for targeted mutations in S. epidermidis (Brophy et al., 2018; Monk et al., 2012; Winstel et al., 2016). Previously described genetic methods have advanced the field, but they 
are time-consuming and effective only for a few specific strains of $S$. epidermidis (Monk et al., 2012; Winstel et al., 2016) or able to make insertions only at specific genomic sites (Brophy et al., 2018). Here, we introduce a new method to genetically engineer $S$. epidermidis that is efficient and works in the vast majority of primary human $S$. epidermidis isolates. Driven by the observation that specific host pattern recognition receptor (PRR) mutants altered or abolished components of the adaptive immune response to S. epidermidis, we used this method to remove or alter components of the $S$. epidermidis cell wall, which is a rich source of candidate PRR ligands.

Under conditions of physiologic colonization, we found that $S$. epidermidis cell envelope mutants elicit marked changes in the composition and function of the T cell population in the skin. Modifications to the lipid versus carbohydrate moieties of surface structures yield distinct and unexpected shifts in the T cell response due to sensing of microbial components by C-type lectin receptors and Toll-like receptors. Our data reveal two unexpected findings. First, S. epidermidis cell wall ligands are sensed combinatorially by host receptors, creating the potential for much greater specificity and control of immune output toward commensal strains than previously appreciated. Second, while mutants in the S. epidermidis envelope elicit marked differences in the T cell number and quality during colonization, they do not alter the intensity of the T cell response to $S$. epidermidis intradermally, while impacting defined innate cell responses. These data indicate that the molecular components of the $S$. epidermidis envelope are 'commensalism factors' that guide the homeostatic immune response during colonization but not the anti-infection immune response in the context of invasion and breach of the skin barrier. These findings establish a molecular mechanism for homeostatic immune induction by $S$. epidermidis, and they open the door to exogenous control of the host pathways governing immune modulation by skin commensals.

\section{A method for genetically modifying primary S. epidermidis isolates}

Targeted genetic modification of $S$. epidermidis has been challenging for two reasons. First, $S$. epidermidis has multiple stringent restriction systems that differ substantially among strains (Lee et al., 2016; Monk et al., 2012, 2015). Among human commensal skin bacteria, S. epidermidis has a relatively large pan-genome with a high degree of genetic variation among individuals (20\% variability compared to $5 \%$ for Cutibacterium acnes) (Oh et al., 2016). As a result, genetic methods developed for Staphylococcus aureus that rely on bypassing strain-specific restriction-modification systems (Monk et al., 2015) are difficult to apply to $S$. epidermidis. Second, like many other Gram-positive bacteria, S. epidermidis can only be electroporated inefficiently due to a thick cell wall (Moran et al., 2018). Published methods demonstrate a transformation efficiency in $S$. epidermidis strain RP62a of approximately $20 \mathrm{cfu} / \mu \mathrm{g}$ of plasmid DNA compared to $10^{3} \mathrm{cfu} / \mu \mathrm{g}$ for $S$. aureus (Monk et al., 2012) and $10^{9} \mathrm{cfu} / \mu \mathrm{g}$ for $E$. coli using a standard protocol (Inoue et al., 1990). 
To bypass poor electroporation efficiency, a genetic approach was recently described that involves transduction with bacteriophage $\Phi 187$ from an engineered restriction-deficient S. aureus (PS187 $\Delta h s d R$ $\triangle$ sauPSI) to $S$. epidermidis or other coagulase-negative Staphylococcus species on the basis of their similarity in wall teichoic acid structure (Winstel et al., 2013, 2016). Although this method works well for a specific clade of $S$. epidermidis strains, it is time-consuming, requires prolonged phage propagation, and is useful only for certain strains of $S$. epidermidis with efficient phage adsorption capacity; for example, this method does not work for S. epidermidis ATCC 12228. Given the high variability of phage specificity across S. epidermidis strains, the application of this phage-based method across many primary human isolates of $S$. epidermidis is limited, thus restricting our ability to study strain-strain and strain-host interactions.

Here, we introduce a novel electroporation and heat shock-based method that takes advantage of the methylase-deficient $(\Delta d c m)$ E. coli strain DC10B (Monk et al., 2012) and includes additional measures that increase electroporation efficiency and decrease restriction-modification efficiency. Critical elements of our method include cultivating $S$. epidermidis in hyperosmolar sorbitol, washing thoroughly in high volume $10 \%$ glycerol, a heat shock before or after electroporation, and a prolonged recovery period prior to plating (Figure 1A). Our approach does not restrict the efficiency of cloning to phage type and does not require specialized knowledge of strain-specific restriction systems. Using this method, we were able to construct mutations in most of the $S$. epidermidis strains we tested, include $>10$ primary human isolates from diverse phylogenetic groups (Figure 1B-C).

\section{Specific pattern recognition receptors drive the adaptive immune response to $S$. epidermidis during skin colonization}

Our genetic method provides a powerful new tool to probe the mechanisms by which S. epidermidis interacts with host immune cells during colonization. In order to inform a candidate gene approach for immune modulatory microbial ligands, we first set out to identify the host receptors required for an adaptive immune response to $S$. epidermidis, using a previously established system in which $S$. epidermidis is applied topically and immune cells are isolated and phenotyped (Figure 2A) (Naik et al., 2012).

When topically associated onto wild-type specific pathogen free (SPF) mice without any barrier breach or inflammation, S. epidermidis strain LM087 promote the accumulation of IFN- $\gamma$ and IL-17Aproducing CD8+ (Tc1, Tc17) and CD4+ T cells (Th1,Th17), as previously described (Figure 2B) (Harrison et al., 2019; Linehan et al., 2018; Naik et al., 2012, 2015). This homeostatic immune response protects against infection by diverse pathogens, including Leishmania major and Candida albicans (Naik et al., 2012, 2015), and promotes tissue repair after injury (Linehan et al., 2018). However, the S. epidermidis ligands and host receptors responsible for triggering this response and differentially promoting distinct 
classes of T cells remain unknown. Therefore, we set out to test the contribution from different classes of pattern recognition receptors.

In a complete Toll-like receptor deficient mouse (T/r-/-)(Sivick et al., 2014), S. epidermidis colonization was impaired in its ability to induce $\mathrm{CD}^{+} \mathrm{T}$ cells but was still able to stimulate CD4+ $\mathrm{T}$ cells (Figure 2B, S1A). To determine which specific Toll-like receptors (TLRs) may be involved, we screened a panel of individual mouse TLR knockouts (Figure 2C-E, S1B-E). As expected, deletion of t/r4 and t/r9 did not decrease the skin T cell response, since their cognate ligands (lipopolysaccharide and viral RNA, respectively) are not present in S. epidermidis. In contrast, deletion of TIr2, TIr3, or TIr7 resulted in a reduction of the characteristic $\mathrm{CD} 8^{+} \mathrm{T}$ cell response, while the CD4+ $\mathrm{T}$ cell response remained unchanged (Figure 2C-E, S1B-E). On the other hand, deletion of TIr5 reduced the CD4+ $4^{+}$cell response specifically (Figure 2C, S1-D). Interestingly, in the T/r3-/- and TIr7-/- mice, IFN- $\gamma$-producing CD8+ T cells were dominantly affected, whereas in the T/r2-/- mice, although CD8+ T cell responses were decreased, the ability of these cells to produce IFN- $\gamma$ - or IL-17A-producing was unaffected (Figure 2D-E, S1C-E). These results suggest that specific TLRs do not just broadly sense $S$. epidermidis under conditions of colonization; distinct TLRs specifically control CD8+ versus CD4+ $\mathrm{T}$ cell responses and also differentially tune the cytokine polarization and function of $T$ cells in the skin.

We next considered C-type lectin receptors (CLRs), a family of $>100$ glycan receptors thought to sense diverse fungal and bacterial molecules, including fungal $\beta$-glucan (del Fresno et al., 2018), Mycobacterium tuberculosis trehalose dimycolate (Ishikawa et al., 2009), and Helicobacter pylori lipopolysaccharide (Devi et al., 2015). Given that the Staphylococcus cell surface is rich in glycans and glycolipids, we set out to test whether CLRs are involved in the immune response to $S$. epidermidis. We found that deletion of Clec7a (Dectin-1) decreased CD8 ${ }^{+} \mathrm{T}$ cell stimulation without affecting CD4+ ${ }^{+}$cell stimulation, similarly to deletion of TIr2 (Figure 3A-B). Deletion of Clec7a also did not change the balance of IFN- $\gamma$ and IL-17A secretion by T cells, similarly to deletion of TIr2 (Figure 3B). In mice lacking both TLR2 and Dectin-1, the CD8+ T cell response was significantly decreased but the CD4+ T cell response remains unaffected, similarly to the single knockouts (Figure $3 \mathbf{C}$ ). Therefore, either distinct pattern recognition receptors are important for the $\mathrm{CD} 4{ }^{+} \mathrm{T}$ cell response, or that $\mathrm{CD} 4^{+} \mathrm{T}$ cell stimulation relies on more redundant sensing of microbial ligands. In both Clec7a-/- and T/r2-/- mice, we also observed a compensatory increase in $\gamma \delta$-T cell stimulation by $S$. epidermidis (Figure S2A-B). Blocking this $\gamma \delta$-T cell response did not alter the effect of TLR2 or CLEC7A on CD8 ${ }^{+}$T cell stimulation, suggesting that the $\alpha \beta-T$ cell response to colonizing $S$. epidermidis is independent from the $\gamma \delta$-T cell response (Figure S2C-D). Instead, the $\gamma \delta$-T cell response may be a secondary effect when the $\alpha \beta$-T cell response is unable to be stimulated. 


\section{Sensing of S. epidermidis by epithelial and hematopoietic cells within the skin}

During bacterial colonization of the skin surface, immune sensing can be mediated by epithelial cells, such as keratinocytes or neurons, or by traditional antigen-presenting cells, such as dendritic cells (Kashem et al., 2015; Lai et al., 2009; Naik et al., 2015). To determine whether the expression of CLEC7A on the epithelial or the hematopoietic compartment in the skin is responsible for driving CD8+ ${ }^{+}$cell stimulation by $S$. epidermidis, we generated bone-marrow chimeras in wild-type or Clec7a-/-knockout mice (Figure 3D). Surprisingly, replacing the myeloid compartment in wild-type with donor Clec7a-/- cells did not alter either the $\mathrm{CD}^{+}$or $\mathrm{CD}^{+} \mathrm{T}$ cell response to $S$. epidermidis colonization (Figure 3D, S2E). In contrast, Clec7a-/- recipient mice with a bone marrow transplant from wild-type mice phenocopied the loss of $\mathrm{CD}^{+} \mathrm{T}$ cell stimulation observed in the Clec7a-/- knockout (Figure 3D, S2E). Although Langerhans cells are a radiation-resistant population of immune cells in the skin, they likely do not represent an important component to the induction of $\mathrm{CD}^{+} \mathrm{T}$ cell stimulation (Naik et al., 2015). These data suggest that although a specific population of $\mathrm{CD}_{103^{+}}$dendritic cells are required for induction of $\mathrm{CD}^{+} \mathrm{T}^{+}$cell responses (Naik et al., 2015), C-type lectin receptor sensing of microbial molecules most likely by tissueresident non-myeloid cells is also required.

\section{S. epidermidis cell envelope mutants induce distinct changes to adaptive immune response}

In light of our observation that host TLR2 and CLEC7A signaling are required for the CD8+ $T$ cell response to colonizing $S$. epidermidis, we hypothesized that the relevant microbial ligands for the induction of these cells would be lipids, glycolipids, or glycans, which are found in abundance on bacterial cell surfaces (Blanc et al., 2013; Brown et al., 2013). Using the genetic method described above (Figure 1A), we created a panel of mutants of the primary human isolate $S$. epidermidis LM087 with defined alterations in cell surface structures. Based on homology to well-described genes in S. aureus (Table S1), we made deletions in $S$. epidermidis that selectively removed wall teichoic acid $(\Delta \operatorname{tag} O)$, the $\mathrm{D}$-alanine modification on wall and lipoteichoic acid $(\Delta d l t A)$, lipoproteins $(\Delta / g t)$, and cell-wall associated proteins $(\Delta s r t A)($ Figure 4A, S3A-B). We observed that all mutants were capable of colonizing mouse skin at the time of immune phenotyping (Figure 4B). Although we observed, minor variability in the level of colonization between the various mutants, there was no significant correlation between CFU count and $\mathrm{CD}^{+}$or $\mathrm{CD}^{+}{ }^{+} \mathrm{T}$ cell responses (Figure S4D).

Eliminating $S$. epidermidis lipoproteins and D-alanylation of teichoic acids $(\Delta / g t$ and $\Delta d l t A$, respectively) almost completely abolished CD8+ T cell induction without a significant effect on CD4+ T cell stimulation (Figure 4C-D, S3C-D), similar to the deletion of TIr2 and Clec7a in the host. In contrast, the removal of wall teichoic acids $(\Delta \operatorname{tag} O)$ significantly impaired both $\mathrm{CD}^{+}$and $\mathrm{CD}^{+} \mathrm{T}$ cell accumulation 
227 observations. First, S. epidermidis LM087 is capable of stimulating CD8 ${ }^{+}$T cells, whereas $S$. aureus 228 NCTC8325 is not (Naik et al., 2015). This raises the possibility that a molecular difference in the cell 229 envelopes of these two strains could contribute to their differential capacity to stimulate immune signaling. 230 Second, S. aureus and S. epidermidis teichoic acids are predicted to vary in a specific way. S. aureus 231 harbors multiple glycosyltransferases that are not found in S. epidermidis; these include TarM and TarS, 232 which attach $\mathrm{N}$-acetylglucosamine (GlcNAc) moieties to the repeating unit of wall teichoic acid (Sobhanifar 233 et al., 2015, 2016; Xia et al., 2010) (Table S1).

We hypothesized that some of these GlcNAc moieties may block immune recognition of $S$. aureus wall teichoic acid. To explore this possibility, we engineered S. epidermidis to express TarS and TarM on a medium-copy plasmid; mice colonized with this mutant exhibit decreased $\mathrm{CD}^{+}$and unchanged $\mathrm{CD}^{+}{ }^{+} \mathrm{T}$ cell stimulation (Figure 4E). The effect is less profound than complete deletion of WTA $(\Delta \operatorname{tag} O)$ or Dalanine modification of teichoic acids $(\Delta d / t A)$, perhaps due to incomplete or inefficient glycosylation of $S$. epidermidis teichoic acids by TarS/TarM. But consistent with the deletion of $\operatorname{tag} O$ and $d / t A$, addition of tarS and tarM disproportionately affected IFN $\gamma$-producing CD8+ ${ }^{+}$T cells over IL17A-producing CD8 ${ }^{+} \mathrm{T}_{\text {cells }}$ (Figure 4E). Together, these data suggest that sensing glycan moieties on the $S$. epidermidis surface modulates $\mathrm{CD}^{+} \mathrm{T}$ cell stimulation, with a disproportionate effect on IFN- $\gamma$ production.

These data also support the idea that $S$. aureus may have evolved to mask its teichoic acids to avoid these commensal $\mathrm{T}$ cell responses, thus leading to increased escape from immune surveillance and increased virulence as well as a loss of the beneficial host homeostatic response. A recent report shows that methicillin-resistant Staphylococcus aureus strains often contain an alternative wall teichoic acid lead to pathogen evasion of humoral immunity (Gerlach et al., 2018). Here, we show an effect of differential teichoic acid glycosylation on cellular immunity. While pathogens like $S$. aureus have altered their immune epitopes to escape immune detection, commensal microbes like $S$. epidermidis may have differentially evolved the same structures to be able to colonize effectively and provoke a measured and specific immune response that benefits host epithelial health and immune barrier function.

Finally, the loss of cell-wall associated proteins $(\Delta s r t A)$ did not affect the adaptive immune response to $S$. epidermidis under conditions of colonization (Figure 4C). Sortase substrates are critical for $S$. aureus pathogenesis (Mazmanian et al., 2000) and infection-associated inflammation in models of infection, such as septic arthritis (Jonsson et al., 2002). These data further highlight that immune responses to $S$. aureus and S. epidermidis are triggered by distinct molecular components of the Staphylococcus cell wall. 
In light of our finding that $S$. epidermidis teichoic acids and lipoproteins are critical to immune signaling during colonization, we next asked whether these molecules are required in a different context: the immune response to $S$. epidermidis during skin invasion. To our surprise, when $S$. epidermidis mutants deficient in wall teichoic acids, teichoic acid D-alanylation, and lipoprotein biogenesis were injected intradermally into the ear, we found that all mutants could robustly induce CD8+ or CD4+ T cell responses to similar levels as wild-type S. epidermidis (Figure 5B, S5), in contrast to the case of topical association. However, there were significant alterations in the stimulation of innate immune populations (Figure 5D). On the other hand, while the absolute number of $\mathrm{T}$ cells was unchanged, the quality of type 1 responses by both $\mathrm{CD}^{+}$and $\mathrm{CD} 8+\mathrm{T}$ cells were significantly decreased with $\Delta \operatorname{tag} \mathrm{O}$ and $\Delta d \mathrm{dtA}$ but not with $\Delta / g t$ (Figure S5). Further, the loss of $\mathrm{D}$-alanylation of teichoic acids $(\Delta d / t A)$ decreased neutrophil infiltration but stimulated the other innate immune populations (Figure 5C). Taken together, these results support the idea that in the context of tissue damage and inflammation, teichoic acids and lipoproteins have a distinct impact on innate inflammatory responses. These data underscore the importance of context (e.g., state of the barrier, tissue site of sensing) to the host immune response to microbes, and they are consistent with context of pathogenic settings. Thus, our findings suggest that the molecular language of commensalism in the skin is distinct from that of pathogen-immune interactions.

\section{DISCUSSION}

Hundreds of bacterial species colonize mammalian barrier sites. Of these, $S$. epidermidis is among the most prevalent: it is present on every human and is typically the single most abundant bacterial species on skin. Given its predominance in the human microbiome, remarkably little is known about the mechanisms by which $S$. epidermidis interacts with the host, due in large part to the inability to genetically manipulate most strains of $S$. epidermidis. This is a challenge common to the study of nearly all of the most common members of the human microbiota. Previous efforts to study $S$. epidermidis-host interactions have focused on characterizing the immune cells that sense S. epidermidis colonization (Lai et al., 2009; Linehan et al., 2018; Naik et al., 2012, 2015). However, the lack of a reliable genetic system for $S$. epidermidis has precluded mechanistic work on the bacterial components of microbiome-host interactions during skin colonization.

The genetic method we introduce here opens the door to discovering the $S$. epidermidis molecules that govern its interactions with the host. Electroporation is a versatile method of introducing foreign DNA into bacteria; the factors that enabled us to apply it to $S$. epidermidis include outgrowth in media containing 
294 washing with a large volume of $10 \%$ glycerol to remove salts, adding a heat shock before or after electroporation (Dorella et al., 2006; Löfblom et al., 2007), and use of a methylase-deficient E. coli strain to produce the donor DNA (Monk et al., 2012). With modest efforts to optimize heat shock time and temperature, these techniques can very likely be generalized to other Gram-positive bacteria that are currently genetically intractable. Notably, these techniques could make it easier to study primary commensal isolates, which have different features than more commonly studied model organisms.

Another strength of our approach is that our experiments involve colonizing native mouse skin with live bacteria, so our immune readout integrates the in situ epithelial and immune signals in their native structure. Previous efforts have characterized purified microbial components in cell culture or in assays of S. epidermidis invasion, but not in the context of colonization (Deininger et al., 2003; Sabaté Brescó et al., 2017; Volz et al., 2018). Our data reveal the role of individual $S$. epidermidis ligands, presented by a colonist through an intact barrier, in triggering specific components of the adaptive immune response. Notably, teichoic acids and lipoproteins have previously been implicated in $S$. aureus pathogenesis (Brown et al., 2012; Hashimoto et al., 2006; Stoll et al., 2005). Their role in commensal immune sensing indicates that similar molecules can elicit highly distinct host responses depending on context (e.g., the site of sensing and the identity of the presenting microbe). Although $S$. epidermidis teichoic acids and lipoproteins are critical for $\mathrm{CD}^{+}$and/or $\mathrm{CD}^{+} \mathrm{T}$ cell responses in the skin during colonization, these molecules are surprisingly dispensable for the anti-pathogen immune response when $S$. epidermidis is injected intradermally. Instead, different $S$. epidermidis cell surface alterations changed the response of distinct innate immune populations. Intradermal injection bypasses the epithelial barrier and disrupts the structural organization of skin immune system. Thus, not only are the microbial molecules that drive immune responses distinct between commensal and pathogenic host contexts, but their interpretation by the immune system and how innate immune signals are transduced to adaptive immune signals are also distinct. The divergence in immune response to the same set of $S$. epidermidis mutants in different contexts of microbial sensing also underscores the difficulty in drawing direct comparisons between in vitro results co-culturing bacteria with immune cells to in vivo responses. Importantly, our data show that the complex glycans and lipoglycans in the cell wall of $S$. epidermidis may have evolved to serve as "commensalism factors" rather than virulence factors.

Similarly, we show that TLRs and CLRs, host receptors described predominantly as sensors of microbial "danger signals" in the context of pathogen invasion, are critical for sensing commensals under homeostatic conditions of skin colonization. TLR2 was previously identified as the receptor for Staphylococcus lipoproteins and lipoteichoic acids that transduces a pro-inflammatory signal (Blanc et al., 2013; Kurokawa et al., 2009, 2012; Schröder et al., 2003). TLR2 was not previously known to participate 
acids can stimulate immune cells through TLR1-, 2-, and 6-independent mechanisms that are not welldefined (Buwitt-Beckmann et al., 2006; Kaesler et al., 2016). We now show that in addition to TLR2, CLRs including (but not limited to) Dectin-1 are required for $\mathrm{T}$ cell stimulation by $S$. epidermidis. Our data complements recent reports that $S$. aureus wall teichoic acids can be sensed by another CLR, Langerin, on Langerhans cells in the skin to induce inflammation (Dalen et al., 2019; van Dalen et al., 2018). Thus, in parallel to the gut, where TLR stimulation by commensal microbiota induces a tissue-protective response (Rakoff-Nahoum et al., 2004), our data demonstrate that TLR and CLR signaling in response to a multiple S. epidermidis surface molecules is also required for a tissue-protective adaptive immune response in the skin.

Previous literature has shown that CLR and TLR signaling pathways can interact either positively or negative to generate a combined immune output (del Fresno et al., 2018). For example, the CLR DCSIGN inhibits TLR4 signaling to block LPS-induced dendritic cell maturation (Doz et al., 2007; Gringhuis et al., 2007). On the other hand, CLEC7A and TLR2 have been shown to cooperate within the same cell to increase inflammatory cytokine production (Gantner et al., 2003). In our case, both the single and double knockouts of host TIr2 and Clec7a, the CD8+ T cell response to colonizing S. epidermidis was dampened but not completely abolished, while the CD4+ $\mathrm{T}$ cell response was largely unaffected. These suggest that involved to generate the CD4+ $\mathrm{T}$ cell response.

Where these pattern recognition receptors are located, and which cell populations are involved to ultimately generate the adaptive immune response to colonizing $S$. epidermidis has also been unclear. Previously, it was shown that antigen presentation by $\mathrm{CD}_{103^{+}}$dendritic cell to $\mathrm{CD}^{+} \mathrm{T}$ cells via a nonclassical MHC I molecule H2-M3 is required for $S$. epidermidis stimulation of CD8+ IL17A-producing T cells during colonization (Linehan et al., 2018; Naik et al., 2015). Here, in addition to antigen-presentation by dendritic cells, we show that $S$. epidermidis activation of the CLR CLEC7A may occur through non-myeloid cells in the skin, and this process is also required to generate the CD8 ${ }^{+} \mathrm{T}$ cell response. Commensal bacteria were previously known to activate TLR signaling in keratinocytes in the setting of skin injury (Lai et al., 2009). Our data now demonstrate that signaling by non-myeloid skin cells likely also occurs during commensal colonization and this signaling may link the tissue context of commensal sensing to the resultant adaptive immune response.

In sum, we developed new methods that enable us to create a panel of systematic cell surface deletions or alterations in the background of a primary human isolate of $S$. epidermidis. Using a model of commensal skin colonization, we dissect the microbial and host components responsible for the $S$. epidermidis-immune communication. Specifically, we show that not only TLRs, but also CLRs and non- 
Our data demonstrate that commensalism and pathogenesis are sensed by a common molecular language, but the host context in which the signal is received governs the inflammatory outcome. Taken together, our work opens the door to a broader and more mechanistic exploration of $S$. epidermidis-host interactions with a wide variety of primary human S. epidermidis isolates. This more mechanistic understanding can in turn provide novel therapeutic targets and methods for modulating immune activation in inflammatory skin diseases.

\section{METHODS}

Mice

Wild-type (WT) C57BL/6 specific pathogen-free mice were purchased from Taconic Farms. B6.[KO]TLR3 N10 (T/r3 ${ }^{--}$), C57BL/6J-CD45a (CD45.1 WT), C57BL/6J x B6.SJL-CD45a/Nai F1 (CD45.1/CD45.2 WT) mice were obtained through the NIAID-Taconic exchange program. B6.129S6-

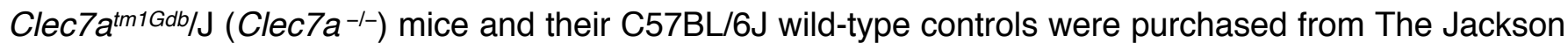
Laboratory. B6.129S1-TIr5tm1/Fv/J (TIr5 ${ }^{-/}$) and B6.129P2-TIrgtmAki (TIr9---) mice were kindly provided by Dr. G. Trinchieri (National Cancer Institute/NIH). B6.129P2-TIr2tmAki (TIr2---) and B6.129P2-TIr $4^{\text {tm1Aki }}$ (TIr4 -/-) mice backcrossed 11 generations onto the C57BL/6 (Taconic) background were generous gifts from

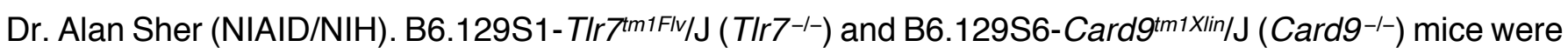
generous gifts from Dr. S. Bolland (NIAID/NIH) and Dr. M. Lionakis (NIAID/NIH), respectively. Tlr2

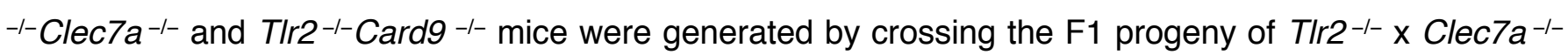

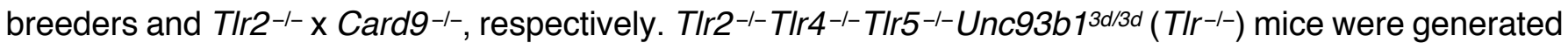
by and obtained from Dr. G. Barton (University of California, Berkeley). For experiments with knockout mice, littermate controls were used as wild-type controls, and/or wild-type (littermate or C57BL/6) and knockout mice were co-housed at 3-5 weeks of age for 2-3 weeks in the same cage, then separated prior to the start of experimental manipulations. All mice were bred and maintained under pathogen-free conditions at an American Association for the Accreditation of Laboratory Animal Care (AAALAC)accredited animal facility at the NIAID and housed in accordance with the procedures outlined in the Guide for the Care and Use of Laboratory Animals. All experiments were performed at the NIAID under an animal study proposal (LISB20E) approved by the NIAID Animal Care and Use Committee or at Stanford University under the animal study protocol (32872) approved by the Stanford Laboratory Animal Care Committee. Sex and age-matched mice between 6 and 12 weeks of age were used for each experiment. When possible, preliminary experiments were performed to determine requirements for samples size, taking in account resources available and ethical, reductionist animal use. In general, each mouse of the 
different experimental groups is reported. Exclusion criteria such as inadequate staining or low cell yield due to technical problems were pre-determined. Animals were assigned randomly to experimental groups.

\section{Genetic engineering of Staphylococcus epidermidis}

To generate electrocompetent cells, S. epidermidis was grown in Difco Brain Heart Infusion media (BD 241810) with $0.5 \mathrm{M}$ sorbitol (BHIS) overnight at $37^{\circ} \mathrm{C}$ with shaking and then back-diluted to an OD of 0.15 to 0.25 . Back-diluted cultures were grown in BHIS until an OD of 0.7 to 0.9 at $37^{\circ} \mathrm{C}$ with shaking. At this time, cultures were placed on ice and then pelleted at $3500 \mathrm{xg}$ for 10 minutes at $4^{\circ} \mathrm{C}$. Cultures were resuspended in equal volume $10 \%$ ice-cold glycerol. Spin and resuspension steps were repeated for a total of four to five $10 \%$ glycerol washes. Each $50 \mathrm{ml}$ of culture OD 0.7 to 0.9 was resuspended in $100 \mathrm{ul}$ of $10 \%$ ice cold glycerol and used for one electroporation reaction. Fresh competent cells were made for each electroporation.

Approximately $1 \mu \mathrm{g}$ of plasmid isolated from DC10B E. coli or $1 \mu \mathrm{g}$ of minicircle plasmid from JCM2 E. coli was added to $100 \mu \mathrm{l}$ of competent S. epidermidis and cells (Johnston et al., 2018; Monk et al., 2012). Method A works for strains LM018, LM061, LM087, LM088, LM095, NIH05001, ATCC12228, SK135, W23144, KPL1815. Method B works for strains ATCC35984 (RP62A), DSM20042, BCM0060. For method $\mathrm{A}$, cells and plasmid in $10 \%$ glycerol were heat-shocked at $56^{\circ} \mathrm{C}$ for 2 minutes, then immediately transferred to a $0.1 \mathrm{~cm}$ cuvette, electroporated, and transferred to $3 \mathrm{ml}$ of room temperature BHIS. For method B, cells and plasmid in 10\% glycerol were pre-warmed at room temperature for 5 minutes, electroporated in a $0.1 \mathrm{~cm}$ cuvette, diluted into $1 \mathrm{ml}$ of BHIS prewarmed to $56^{\circ} \mathrm{C}$ to heat-shock for 2 minutes, and then diluted with $3 \mathrm{ml}$ of room temperature BHIS. For both methods, the electroporation program was $2.5 \mathrm{kV}, 1$ pulse, with a typical time constant of 2.3-2.5 msec using a Bio-Rad Micropulser.

Following heat shock and electroporation, cells in BHIS were recovered at $37^{\circ} \mathrm{C}$ for $1.5-2$ hours if using a replicative plasmid (pLI50, a gift from Chia Lee, Addgene plasmid \#13573) and at $28^{\circ} \mathrm{C}$ for 4 hours if using a temperature-sensitive plasmid (pIMAY, gift from Tim Foster, Addgene plasmid \# 68939) (Lee et al., 1991; Monk et al., 2012). After recovery, cells were spun down at $3500 \mathrm{x} g$ for 10 minutes and plated onto BHIS plates with chloramphenicol $(10 \mu \mathrm{g} / \mathrm{ml})$. For allelic replacement, transformation plates were grown at $28^{\circ} \mathrm{C}$ for $2-3$ days. At this time, single colonies were grown in $\mathrm{BHI} /$ chloramphenicol at $37^{\circ} \mathrm{C}$ overnight, and serial dilutions were plated onto $\mathrm{BHI} / \mathrm{chloramphenicol}$ at $37^{\circ} \mathrm{C}$ overnight to cure the plasmid. Single colonies were then restruck onto $\mathrm{BHI} / \mathrm{chloramphenicol}$ and plates were grown overnight at $37^{\circ} \mathrm{C}$. Colony PCR was done to determine the absence of plasmids. Colonies that successfully lost the plasmid (now integrated into the genome) were grown in $\mathrm{BHI}$ without antibiotics at 28 deg for 6-12 hours, and then plated onto $\mathrm{BHI} /$ anhydrotetracycline $(1 \mu \mathrm{g} / \mathrm{ml})$ for 2 days to select for double crossover events. Colonies were patched onto $\mathrm{BHI} /$ anhydrotetracycline and $\mathrm{BHI} /$ chloramphenicol, grown at 37 degrees overnight, and 
then resultant anhydrotetracycline-resistant but chloramphenicol-sensitive colonies were screened for the appropriate knockout or allelic replacement by colony PCR using flanking primers.

\section{Topical association and intradermal infection of mice with Staphylococcus epidermidis}

Staphylococcus epidermidis strains (NIHLM087 and mutants made in this background) were cultured for 18 hours in tryptic soy broth at $37^{\circ} \mathrm{C}$, not shaking. For topical association of bacteria, each mouse was associated by placing $5 \mathrm{ml}$ of the bacterial suspension, approximately $10^{9} \mathrm{CFU} / \mathrm{ml}$, across the ear skin surface using a sterile cotton swab. Application of bacterial suspension was repeated every other day for a total of four times. In experiments involving topical application of various bacterial species or strains, 18-hour cultures were normalized using $\mathrm{OD}_{600}$ to achieve similar bacterial density (approximately $10^{9}$ colony-forming units $/ \mathrm{ml}$ (CFU/ml). For some experiments, mice were injected intradermally on day 1 in the ear pinnae with $10^{7} \mathrm{CFU}$ of $S$. epidermidis strain NIHLM087 and mutants made in this background. For intradermal injections, immune cell phenotype was assayed at day 5.

\section{Bacteria quantitation}

The ear pinnae of topically associated or unassociated control mice were swabbed with a sterile cotton swab previously soaked in tryptic soy broth. Swabs were streaked on Columbia blood agar plates. Plates were then placed at $37^{\circ} \mathrm{C}$ under aerobic conditions for 18 hours. Colony-forming units (CFU) on each plate were enumerated and the number of CFU was reported per $\mathrm{cm}^{2}$ of skin.

\section{Tissue processing and immune phenotypic analysis}

Cells from the ear pinnae were isolated as previously described (Naik et al., 2012). For detection of basal cytokine potential, single cell suspensions were cultured directly ex vivo in a 96-well U-bottom plate in complete medium (RPMI 1640 supplemented with 10\% fetal bovine serum (FBS), 2 mM Lglutamine, $1 \mathrm{mM}$ sodium pyruvate and nonessential amino acids, $20 \mathrm{mM}$ HEPES, $100 \mathrm{U} / \mathrm{ml}$ penicillin, 100 $\mu \mathrm{g} / \mathrm{ml}$ streptomycin, $50 \mathrm{mM} \beta$-mercaptoethanol) and stimulated with $50 \mathrm{ng} / \mathrm{ml}$ phorbol myristate acetate (PMA) (Sigma-Aldrich) and $5 \mu \mathrm{g} / \mathrm{ml}$ ionomycin (Sigma-Aldrich) in the presence of brefeldin A (GlogiPlug, BD Biosciences) for 2.5 hours at $37^{\circ} \mathrm{C}$ in $5 \% \mathrm{CO}_{2}$. After stimulation, cells were assessed for intracellular cytokine production as described below. Single cell suspensions were incubated with combinations of the following fluorophore-conjugated antibodies against surface markers:, CD4 (RM4-5), CD8 $\beta$ (eBioH3517.2), CD11b (M1/70), CD19 (6D5), CD45 (30-F11), CD45.1 (A20), CD45.2 (104), CD49b (DX5), CD64 (FA-11), CD90.2 (53-2.1), CD117 (2B8), FceRI (MAR-1), Ly6C (HK1.4), Ly6G (1A8), MHC-II (M5/114.15.2), NK1.1 (PK136), Siglec-F (E50-2440), TCR (H57-597), $\gamma \delta T C R$ (eBioGL3), and TCR V $\gamma 2$ (UC3-10A6) in Hank's buffered salt solution (HBSS) for $20 \mathrm{~min}$ at $4^{\circ} \mathrm{C}$ and then washed. LIVE/DEAD 
463 Fixable Blue Dead Cell Stain Kit (Invitrogen Life Technologies) was used to exclude dead cells. Cells were 464 then fixed for $30 \mathrm{~min}$ at $4^{\circ} \mathrm{C}$ using the fixation/permeabilization buffer supplied with the BD 465 Cytofix/Cytoperm (Becton Dickinson) and washed twice with permeabilization buffer. For intracellular 466 staining, cells were then stained with fluorochrome-conjugated antibody against IFN- $\gamma$ (XMG-1.2), IL-17A 467 (eBio17B7) and Foxp3 (FJK-16s) in permeabilization buffer supplied with the BD Cytofix/Cytoperm kit (BD 468 Biosciences) for 1 hour at $4^{\circ} \mathrm{C}$. Each staining was performed in the presence of purified anti-mouse $469 \mathrm{CD16} / 32$ (clone 93) and $0.2 \mathrm{mg} / \mathrm{ml}$ purified rat gamma globulin (Jackson Immunoresearch). All antibodies 470 were purchased from eBioscience (Life Technologies), Biolegend, or BD Biosciences. Cell acquisition was performed on an LSR Fortessa or LSR II flow cytometer using FACSDiVa software (BD Biosciences) and data were analyzed using FlowJo software (TreeStar).

473

\section{Bone marrow chimera}

Recipient mice ( $\mathrm{Tl}_{\mathrm{r}} \mathrm{-}^{--}, \mathrm{Clec7a}^{-/-}$or congenic CD45.1 WT) were given lethal total body irradiation $(1,200$ rads) and reconstituted the same day intravenously with 10 million bone marrow cells isolated from tibial and femoral bones of Tlr2 ${ }^{-1-}, \mathrm{Clec7a}^{-1-}$ or congenic CD45.1/CD45.2 WT mice. Irradiated and reconstituted mice were given Bactrim (sulfamethoxazole $[150 \mathrm{mg} / \mathrm{ml}]$ and $N$-trimethoprim $[30 \mathrm{mg} / \mathrm{ml}]$ ) in their drinking water for 2 weeks and switched thereafter to sterile drinking water. Mice were allowed to 480 reconstitute for 6-8 weeks before topical association with S. epidermidis.

\section{$\gamma \delta$-T cell depletion}

For $\gamma \delta$ T-cell depletion, mice were treated intraperitoneally with $0.5 \mathrm{mg}$ of anti- $\gamma \delta$ antibody (clone 484 UC7-13D5), or rat lgG2b isotype control antibody (clone LTF-2, BioXCell) every other day, starting the day before the first association.

\section{Statistics}

Data are presented as mean \pm standard error of the mean (SEM) or mean \pm standard deviation 489 (SD). Group sizes were determined based on the results of preliminary experiments. Mice were assigned 490 at random groups. Mouse studies were not performed in a blinded fashion. Generally, each mouse of the 491 different experimental groups is reported. Statistical significance was determined using two-tailed unpaired 492 Student's $t$-test under the untested assumption of normality. All statistical analysis was calculated using 493 Prism software (GraphPad). Differences were considered to be statistically significant when $p<0.05$. 


\section{REFERENCES}

496 Blanc, L., Castanier, R., Mishra, A.K., Ray, A., Besra, G.S., Sutcliffe, I., Vercellone, A., and Nigou, J. 497 (2013). Gram-Positive Bacterial Lipoglycans Based on a Glycosylated Diacylglycerol Lipid Anchor Are 498 Microbe-Associated Molecular Patterns Recognized by TLR2. PLoS ONE 8.

499 Brophy, J.A.N., Triassi, A.J., Adams, B.L., Renberg, R.L., Stratis-Cullum, D.N., Grossman, A.D., and 500 Voigt, C.A. (2018). Engineered integrative and conjugative elements for efficient and inducible DNA 501 transfer to undomesticated bacteria. Nat. Microbiol. 3, 1043.

502

503

504

505 506

507 508 509

510

511

512

513

514

515

516

517

518

519

520

521

522

523

524

525

526

527

528

529

530

531

Brown, S., Xia, G., Luhachack, L.G., Campbell, J., Meredith, T.C., Chen, C., Winstel, V., Gekeler, C., Irazoqui, J.E., Peschel, A., et al. (2012). Methicillin resistance in Staphylococcus aureus requires glycosylated wall teichoic acids. Proc. Natl. Acad. Sci. 109, 18909-18914.

Brown, S., Jr, J.P.S.M., and Walker, S. (2013). Wall Teichoic Acids of Gram-Positive Bacteria. Annu. Rev. Microbiol. 67, 313-336.

Buwitt-Beckmann, U., Heine, H., Wiesmüller, K.-H., Jung, G., Brock, R., Akira, S., and Ulmer, A.J. (2006). TLR1- and TLR6-independent Recognition of Bacterial Lipopeptides. J. Biol. Chem. 281, 90499057.

Dalen, R. van, Diaz, J.S.D.L.C., Rumpret, M., Fuchsberger, F.F., Teijlingen, N.H. van, Hanske, J., Rademacher, C., Geijtenbeek, T.B.H., Strijp, J.A.G. van, Weidenmaier, C., et al. (2019). Langerhans Cells Sense Staphylococcus aureus Wall Teichoic Acid through Langerin To Induce Inflammatory Responses. MBio 10, e00330-19.

van Dalen, R., De La Cruz Diaz, J.S., Rumpret, M., Fuchsberger, F.F., van Teijlingen, N.H., Hanske, J., Rademacher, C., Geijtenbeek, T.B.H., Van Strijp, J.A.G., Weidenmaier, C., et al. (2018). Staphylococcus aureus wall teichoic acid is a pathogen-associated molecular pattern that is recognized by langerin (CD207) on skin Langerhans cells.

Deininger, S., Stadelmaier, A., Aulock, S. von, Morath, S., Schmidt, R.R., and Hartung, T. (2003). Definition of Structural Prerequisites for Lipoteichoic Acid-Inducible Cytokine Induction by Synthetic Derivatives. J. Immunol. 170, 4134-4138.

Devi, S., Rajakumara, E., and Ahmed, N. (2015). Induction of Mincle by Helicobacter pylori and consequent anti-inflammatory signaling denote a bacterial survival strategy. Sci. Rep. 5.

Dorella, F.A., Estevam, E.M., Cardoso, P.G., Savassi, B.M., Oliveira, S.C., Azevedo, V., and Miyoshi, A. (2006). An improved protocol for electrotransformation of Corynebacterium pseudotuberculosis. Vet. Microbiol. 114, 298-303.

Doz, E., Rose, S., Nigou, J., Gilleron, M., Puzo, G., Erard, F., Ryffel, B., and Quesniaux, V.F.J. (2007). Acylation Determines the Toll-like receptor (TLR)-dependent Positive Versus TLR2-, Mannose Receptor, and SIGNR1-independent Negative Regulation of Pro-inflammatory Cytokines by Mycobacterial Lipomannan. J. Biol. Chem. 282, 26014-26025.

del Fresno, C., Iborra, S., Saz-Leal, P., Martínez-López, M., and Sancho, D. (2018). Flexible Signaling of Myeloid C-Type Lectin Receptors in Immunity and Inflammation. Front. Immunol. 9. 
532 Gantner, B.N., Simmons, R.M., Canavera, S.J., Akira, S., and Underhill, D.M. (2003). Collaborative Induction of Inflammatory Responses by Dectin-1 and Toll-like Receptor 2. J. Exp. Med. 197, 11075341117.

535 Gerlach, D., Guo, Y., Castro, C.D., Kim, S.-H., Schlatterer, K., Xu, F.-F., Pereira, C., Seeberger, P.H., 536 Ali, S., Codée, J., et al. (2018). Methicillin-resistant Staphylococcus aureus alters cell wall glycosylation 537 to evade immunity. Nature 563, 705.

538 Grice, E.A., Kong, H.H., Conlan, S., Deming, C.B., Davis, J., Young, A.C., Program, N.C.S., Bouffard, 539 G.G., Blakesley, R.W., Murray, P.R., et al. (2009). Topographical and Temporal Diversity of the Human 540 Skin Microbiome. Science 324, 1190-1192.

541 Gringhuis, S.I., den Dunnen, J., Litjens, M., van het Hof, B., van Kooyk, Y., and Geijtenbeek, T.B.H. 542 (2007). C-Type Lectin DC-SIGN Modulates Toll-like Receptor Signaling via Raf-1 Kinase-Dependent 543 Acetylation of Transcription Factor NF-kB. Immunity 26, 605-616.

544 Gründling, A., and Schneewind, O. (2007). Genes Required for Glycolipid Synthesis and Lipoteichoic 545 Acid Anchoring in Staphylococcus aureus. J. Bacteriol. 189, 2521-2530.

546 Harrison, O.J., Linehan, J.L., Shih, H.-Y., Bouladoux, N., Han, S.-J., Smelkinson, M., Sen, S.K., Byrd, 547 A.L., Enamorado, M., Yao, C., et al. (2019). Commensal-specific T cell plasticity promotes rapid tissue 548 adaptation to injury. Science 363 , eaat6280.

549 Hashimoto, M., Tawaratsumida, K., Kariya, H., Kiyohara, A., Suda, Y., Krikae, F., Kirikae, T., and Götz, 550 F. (2006). Not Lipoteichoic Acid but Lipoproteins Appear to Be the Dominant Immunobiologically Active 551 Compounds in Staphylococcus aureus. J. Immunol. 177, 3162-3169.

Inoue, H., Nojima, H., and Okayama, H. (1990). High efficiency transformation of Escherichia coli with plasmids. Gene 96, 23-28.

Ishikawa, E., Ishikawa, T., Morita, Y.S., Toyonaga, K., Yamada, H., Takeuchi, O., Kinoshita, T., Akira, S., Yoshikai, Y., and Yamasaki, S. (2009). Direct recognition of the mycobacterial glycolipid, trehalose dimycolate, by C-type lectin Mincle. J. Exp. Med. 206, 2879-2888.

Johnston, C.D., Cotton, S.L., Rittling, S.R., Starr, J.R., Borisy, G., Dewhirst, F., and Lemon, K.P. (2018). SyngenicDNA: stealth-based evasion of restriction-modification barriers during bacterial genetic engineering. BioRxiv 387985.

Jonsson, I.-M., Mazmanian, S.K., Schneewind, O., Verdrengh, M., Bremell, T., and Tarkowski, A. (2002). Murine Septic Arthritis. J. Infect. Dis. 185, 1417-1424.

Kaesler, S., Skabytska, Y., Chen, K.-M., Kempf, W.E., Volz, T., Köberle, M., Wölbing, F., Hein, U., Hartung, T., Kirschning, C., et al. (2016). Staphylococcus aureus-derived lipoteichoic acid induces temporary T-cell paralysis independent of Toll-like receptor 2. J. Allergy Clin. Immunol. 138, 780-790.e6. Protective Cutaneous Immunity. Immunity 43, 515-526. 
571 binding Lipoprotein of Staphylococcus aureus Functions as a Native Ligand for Toll-like Receptor 2. J. 572 Biol. Chem. 284, 8406-8411.

573 Kurokawa, K., Ryu, K.-H., Ichikawa, R., Masuda, A., Kim, M.-S., Lee, H., Chae, J.-H., Shimizu, T., 574 Saitoh, T., Kuwano, K., et al. (2012). Novel Bacterial Lipoprotein Structures Conserved in Low-GC 575 Content Gram-positive Bacteria Are Recognized by Toll-like Receptor 2. J. Biol. Chem. 287, 1317057613181.

577 Lai, Y., Di Nardo, A., Nakatsuji, T., Leichtle, A., Yang, Y., Cogen, A.L., Wu, Z.-R., Hooper, L.V., von 578 Aulock, S., Radek, K.A., et al. (2009). Commensal bacteria regulate TLR3-dependent inflammation 579 following skin injury. Nat. Med. 15, 1377-1382.

580 Lee, C.Y., Buranen, S.L., and Zhi-Hai, Y. (1991). Construction of single-copy integration vectors for 581 Staphylococcus aureus. Gene 103, 101-105.

582 Lee, J.Y.H., Monk, I.R., Pidot, S.J., Singh, S., Chua, K.Y.L., Seemann, T., Stinear, T.P., and Howden, 583 584

585

586

587

B.P. (2016). Functional analysis of the first complete genome sequence of a multidrug resistant sequence type 2 Staphylococcus epidermidis. Microb. Genomics 2.

Linehan, J.L., Harrison, O.J., Han, S.-J., Byrd, A.L., Vujkovic-Cvijin, I., Villarino, A.V., Sen, S.K., Shaik, J., Smelkinson, M., Tamoutounour, S., et al. (2018). Non-classical Immunity Controls Microbiota Impact on Skin Immunity and Tissue Repair. Cell 172, 784-796.e18.

591

592

593

594

595

596

597

598

599

600

601

602

603

604

605

606

607

608
Löfblom, J., Kronqvist, N., Uhlén, M., Ståhl, S., and Wernérus, H. (2007). Optimization of electroporationmediated transformation: Staphylococcus carnosus as model organism. J. Appl. Microbiol. 102, 736747.

Mazmanian, S.K., Liu, G., Jensen, E.R., Lenoy, E., and Schneewind, O. (2000). Staphylococcus aureus sortase mutants defective in the display of surface proteins and in the pathogenesis of animal infections. Proc. Natl. Acad. Sci. U. S. A. 97, 5510-5515.

Monk, I.R., Shah, I.M., Xu, M., Tan, M.-W., and Foster, T.J. (2012). Transforming the Untransformable: Application of Direct Transformation To Manipulate Genetically Staphylococcus aureus and Staphylococcus epidermidis. MBio 3.

Monk, I.R., Tree, J.J., Howden, B.P., Stinear, T.P., and Foster, T.J. (2015). Complete Bypass of Restriction Systems for Major Staphylococcus aureus Lineages. MBio 6.

Moran, J.L., Dingari, N.N., Garcia, P.A., and Buie, C.R. (2018). Numerical study of the effect of soft layer properties on bacterial electroporation. Bioelectrochemistry 123, 261-272.

Naik, S., Bouladoux, N., Wilhelm, C., Molloy, M.J., Salcedo, R., Kastenmuller, W., Deming, C., Quinones, M., Koo, L., Conlan, S., et al. (2012). Compartmentalized Control of Skin Immunity by Resident Commensals. Science 337, 1115-1119.

Naik, S., Bouladoux, N., Linehan, J.L., Han, S.-J., Harrison, O.J., Wilhelm, C., Conlan, S., Himmelfarb, S., Byrd, A.L., Deming, C., et al. (2015). Commensal-dendritic-cell interaction specifies a unique protective skin immune signature. Nature 520, 104-108.

Oh, J., Byrd, A.L., Park, M., Kong, H.H., and Segre, J.A. (2016). Temporal Stability of the Human Skin Microbiome. Cell 165, 854-866. 
609 Otto, M. (2009). Staphylococcus epidermidis - the "accidental" pathogen. Nat. Rev. Microbiol. 7, 555610567.

611 Rakoff-Nahoum, S., Paglino, J., Eslami-Varzaneh, F., Edberg, S., and Medzhitov, R. (2004). Recognition 612 of Commensal Microflora by Toll-Like Receptors Is Required for Intestinal Homeostasis. Cell 118, 229613241.

614 Ridaura, V.K., Bouladoux, N., Claesen, J., Chen, Y.E., Byrd, A.L., Constantinides, M.G., Merrill, E.D., 615 Tamoutounour, S., Fischbach, M.A., and Belkaid, Y. (2018). Contextual control of skin immunity and 616 inflammation by Corynebacterium. J. Exp. Med. 215, 785-799.

617 Rockel, C., Hartung, T., and Hermann, C. (2011). Different Staphylococcus aureus whole bacteria 618 mutated in putative pro-inflammatory membrane components have similar cytokine inducing activity. 619 Immunobiology 216, 316-321.

620 Sabaté Brescó, M., Harris, L.G., Thompson, K., Stanic, B., Morgenstern, M., O’Mahony, L., Richards, 621 622 R.G., and Moriarty, T.F. (2017). Pathogenic Mechanisms and Host Interactions in Staphylococcus epidermidis Device-Related Infection. Front. Microbiol. 8.

Scharschmidt, T.C., Vasquez, K.S., Truong, H.-A., Gearty, S.V., Pauli, M.L., Nosbaum, A., Gratz, I.K., 624 Otto, M., Moon, J.J., Liese, J., et al. (2015). A wave of regulatory T cells into neonatal skin mediates 625 tolerance to commensal microbes. Immunity 43, 1011-1021.

Scharschmidt, T.C., Vasquez, K.S., Pauli, M.L., Leitner, E.G., Chu, K., Truong, H.-A., Lowe, M.M., Sanchez Rodriguez, R., Ali, N., Laszik, Z.G., et al. (2017). Commensal Microbes and Hair Follicle 628 Morphogenesis Coordinately Drive Treg Migration into Neonatal Skin. Cell Host Microbe 21, 467-477.e5.

Schröder, N.W.J., Morath, S., Alexander, C., Hamann, L., Hartung, T., Zähringer, U., Göbel, U.B., 630 631 632 633 Weber, J.R., and Schumann, R.R. (2003). Lipoteichoic Acid (LTA) of Streptococcus pneumoniaeand Staphylococcus aureus Activates Immune Cells via Toll-like Receptor (TLR)-2, Lipopolysaccharidebinding Protein (LBP), and CD14, whereas TLR-4 and MD-2 Are Not Involved. J. Biol. Chem. 278, 15587-15594.

Shiratsuchi, A., Shimizu, K., Watanabe, I., Hashimoto, Y., Kurokawa, K., Razanajatovo, I.M., Park, K.H., Park, H.K., Lee, B.L., Sekimizu, K., et al. (2010). Auxiliary role for d-alanylated wall teichoic acid in Tolllike receptor 2-mediated survival of Staphylococcus aureus in macrophages. Immunology 129, 268-277. deficient mice reveal how innate immune signaling influences Salmonella virulence strategies. Cell Host Microbe 15, 203-213.

Sobhanifar, S., Worrall, L.J., Gruninger, R.J., Wasney, G.A., Blaukopf, M., Baumann, L., Lameignere, E., 641 642 Solomonson, M., Brown, E.D., Withers, S.G., et al. (2015). Structure and mechanism of Staphylococcus aureus TarM, the wall teichoic acid a-glycosyltransferase. Proc. Natl. Acad. Sci. 112, E576-E585. e1006067. 
649 Volz, T., Kaesler, S., Draing, C., Hartung, T., Röcken, M., Skabytska, Y., and Biedermann, T. (2018). Induction of IL-10-balanced immune profiles following exposure to LTA from Staphylococcus epidermidis. Exp. Dermatol. 27, 318-326.

652 Williams, M.R., Costa, S.K., Zaramela, L.S., Khalil, S., Todd, D.A., Winter, H.L., Sanford, J.A., O’Neill, 653 A.M., Liggins, M.C., Nakatsuji, T., et al. (2019). Quorum sensing between bacterial species on the skin 654 protects against epidermal injury in atopic dermatitis. Sci. Transl. Med. 11, eaat8329.

Winstel, V., Liang, C., Sanchez-Carballo, P., Steglich, M., Munar, M., Bröker, B.M., Penadés, J.R., Nübel, U., Holst, O., Dandekar, T., et al. (2013). Wall teichoic acid structure governs horizontal gene transfer between major bacterial pathogens. Nat. Commun. 4, 2345.

658 659

660 661

662

Winstel, V., Kühner, P., Rohde, H., and Peschel, A. (2016). Genetic engineering of untransformable coagulase-negative staphylococcal pathogens. Nat. Protoc. 11, 949-959.

Xia, G., Maier, L., Sanchez-Carballo, P., Li, M., Otto, M., Holst, O., and Peschel, A. (2010). Glycosylation of wall teichoic acid in Staphylococcus aureus by TarM. J. Biol. Chem. jbc.M109.096172.

\section{SUPPLEMENTARY INFORMATION}

Figures S1-S5 are available in the online version of the paper.

\section{ACKNOWLEDGMENTS}

We are deeply indebted to members of the Fischbach Group and Belkaid Group for helpful suggestions and comments on the manuscript. We thank Greg Barton (Berkeley) for the generous gift of $\mathrm{Tl}^{-1-}$ mice (unpublished). We thank the National Institute of Allergy and Infectious Diseases (NIAID) animal facility staff. This work was supported by an A.P. Giannini Foundation Postdoctoral Research Fellowship (Y.E.C.); an HHMI Hanna H. Gray Fellowship (Y.E.C.); NIAID Division of Intramural Research (ZIA-AI001115, ZIAAl001132) (Y.B.); an HHMI-Simons Faculty Scholar Award (M.A.F.); a Fellowship for Science and Engineering from the David and Lucile Packard Foundation (M.A.F.); an Investigators in the Pathogenesis of Infectious Disease award from the Burroughs Wellcome Foundation (M.A.F.); an award from BASF (M.A.F.); an award from the Leducq Foundation (M.A.F.); NIH grants DK110174 (M.A.F.), DK113598 (M.A.F.); the Chan Zuckerberg Biohub (M.A.F.). C.H. is funded by fondation La Roche-Posay, Collège des Enseignants en Dermatologie de France (CEDEF), fondation groupe pasteur mutualité, Société Française de Dermatologie, Philippe Foundation, Fondation pour la Recherche Médicale. This work was supported by the Division of Intramural Research of the National Institute of Allergy and Infectious Diseases (NIAID).

\section{AUTHOR CONTRIBUTIONS}

Y.E.C., N.B., C.H., Y.B., and M.A.F. designed the study and wrote the manuscript. Y.E.C., N.B., C.H., and A.M.M. performed the experiments. 


\section{AUTHOR INFORMATION}

686 M.A.F. is a co-founder and director of Federation Bio. Correspondence and requests for materials should 687 be addressed to and will be fulfilled by the Lead Contact, Michael Fischbach 688 (fischbach@fischbachgroup.org).

689 
A

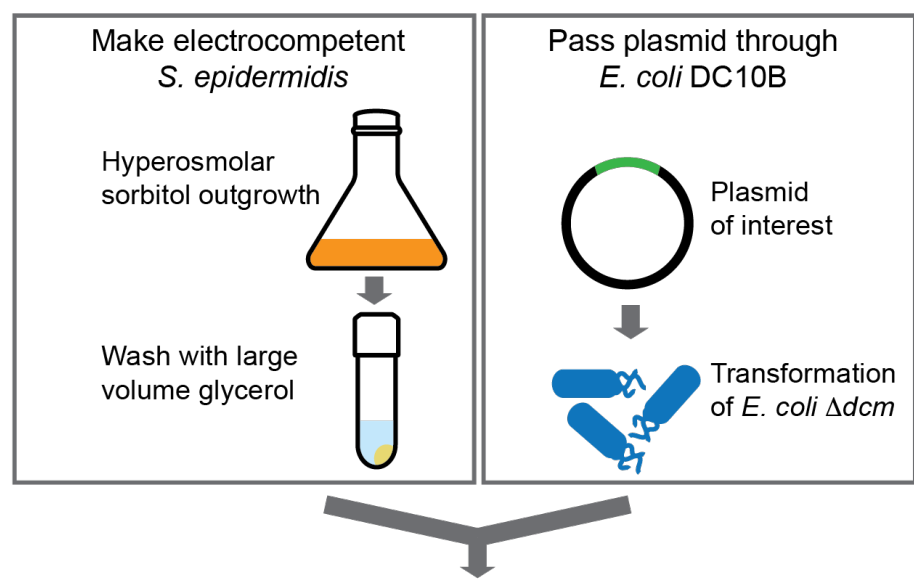

Strain-specific electroporation protocol

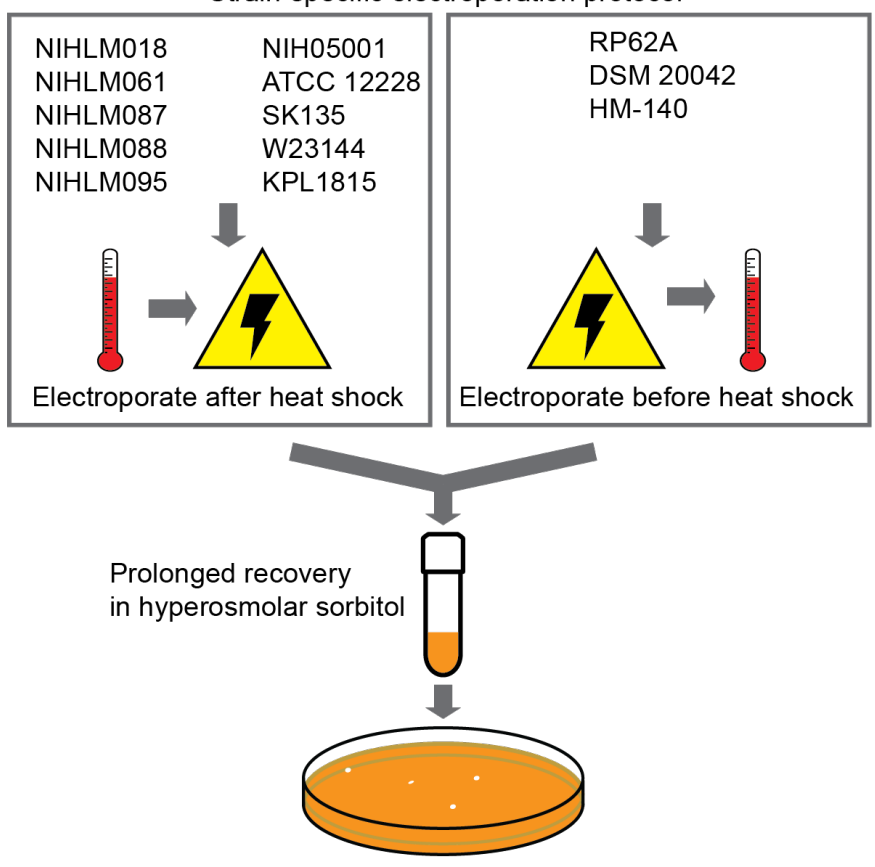

$B$

\begin{tabular}{|l|l|}
\hline S. epidermidis strains successfully engineered & Method \\
\hline NIHLM018 & HS before \\
\hline NIHLM061 & HS before \\
\hline NIHLM087 & HS before \\
\hline NIHLM088 & HS before \\
\hline NIHLM095 & HS before \\
\hline NIH05001 & HS before \\
\hline ATCC 12228 & HS before \\
\hline SK135 & HS before \\
\hline W23144 & HS before \\
\hline KPL1815 & HS before \\
\hline RP62A (syn ATCC 35984) & HS after \\
\hline DSM 20042 (syn CCM 50, NCTC 9865) & HS after \\
\hline HM-140 (syn BCM0060) & HS after \\
\hline S. aureus strains successfully engineered & Method \\
\hline USA300 & HS before \\
\hline NCTC 8325 & HS before \\
\hline SA113 (syn ATCC 35556) & HS before \\
\hline RN4220 & HS before \\
\hline S. epidermidis strains attempted unsuccessfully & \\
\hline NIHLM031 & \\
\hline NIHLM040 & \\
\hline NIHLM049 & \\
\hline DSM 20044 (syn ATCC 14990, CCM 2124, WDCM 00132) \\
\hline
\end{tabular}

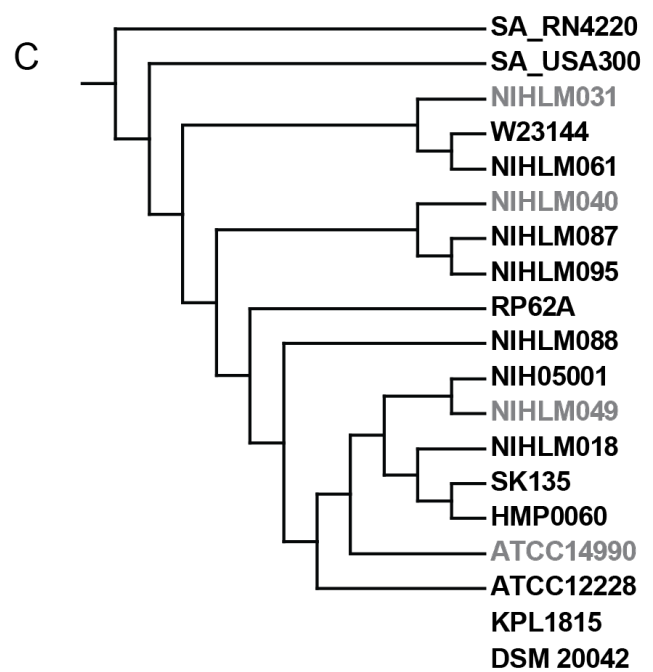

Fig. 1. A new method for genetic modification of $S$. epidermidis. (A) Schematic of $S$. epidermidis 693 genetic engineering method. To optimize electroporation efficiency, the Staphyloccocus strain is grown in 694 media containing hyperosmolar sorbitol, harvested during late-log phase, and thoroughly washed with a 695 large volume of $10 \%$ glycerol to eliminate salts. To bypass stringent restriction systems, the target plasmid 696 is passed through E. coli $\Delta d c m$ and Staphylococcus is subjected to heat shock before or after electroporation. (B) Table of $S$. epidermidis and $S$. aureus strains that have been genetically modified in this work. The two methods differ only in the timing of the heat shock: prior to electroporation ("HS before") or in the recovery medium after electroporation ("HS after"). Our method enables genetic modification of 13/17 S. epidermidis strains attempted. 4/4 S. aureus strains attempted were modified, including those that are restriction-competent. (C) Phylogenetic tree of $S$. epidermidis and $S$. aureus strains demonstrating 
bioRxiv preprint doi: https://doi.org/10.1101/664656; this version posted June 10, 2019. The copyright holder for this preprint (which was not certified by peer review) is the author/funder. All rights reserved. No reuse allowed without permission.

702 that our method works across diverse S. epidermidis strains, including two strains that do not have genome 703 sequences available in NCBI. Black = genetically manipulable. Grey = not genetically manipulable with our 704 method. 
A
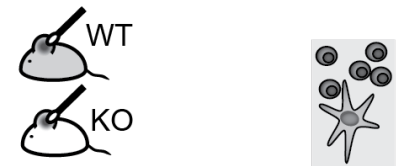

S. epi association immune cell

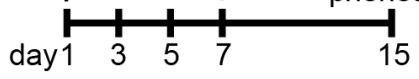

B

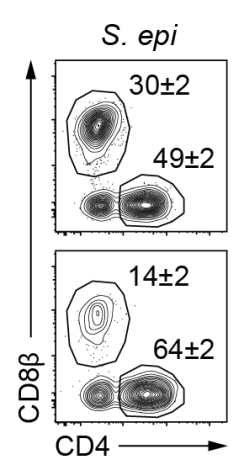

S. epi

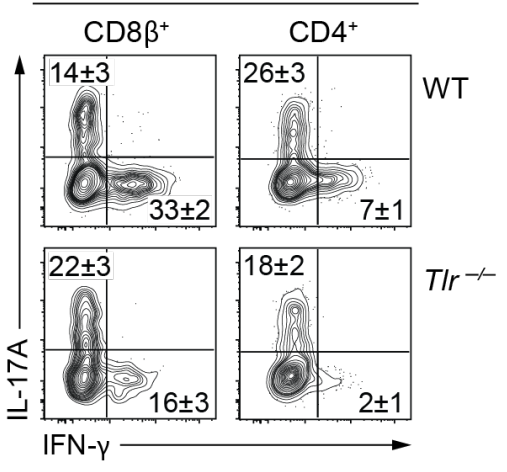

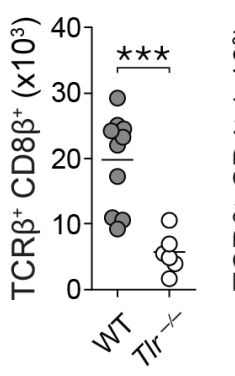

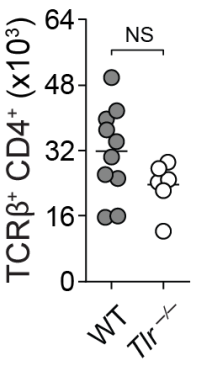

$\mathrm{D}$
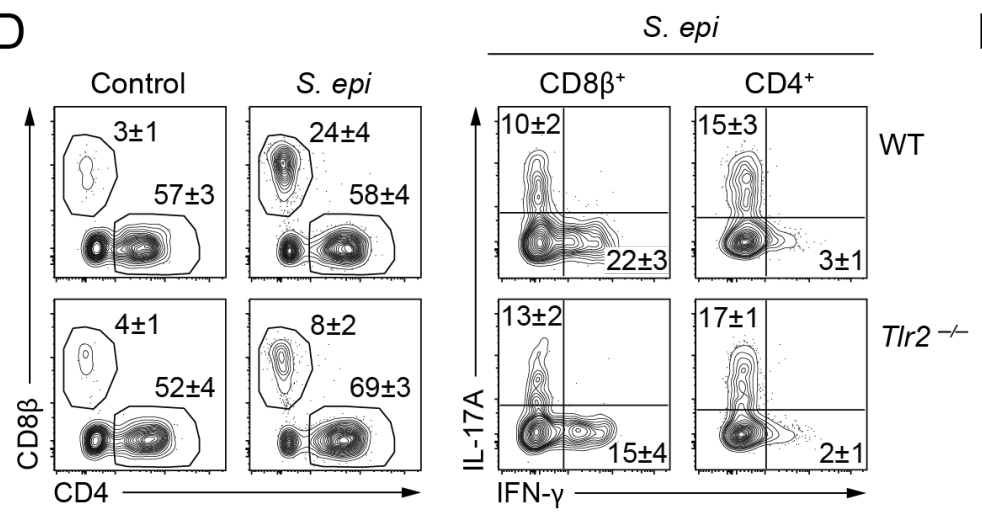

E
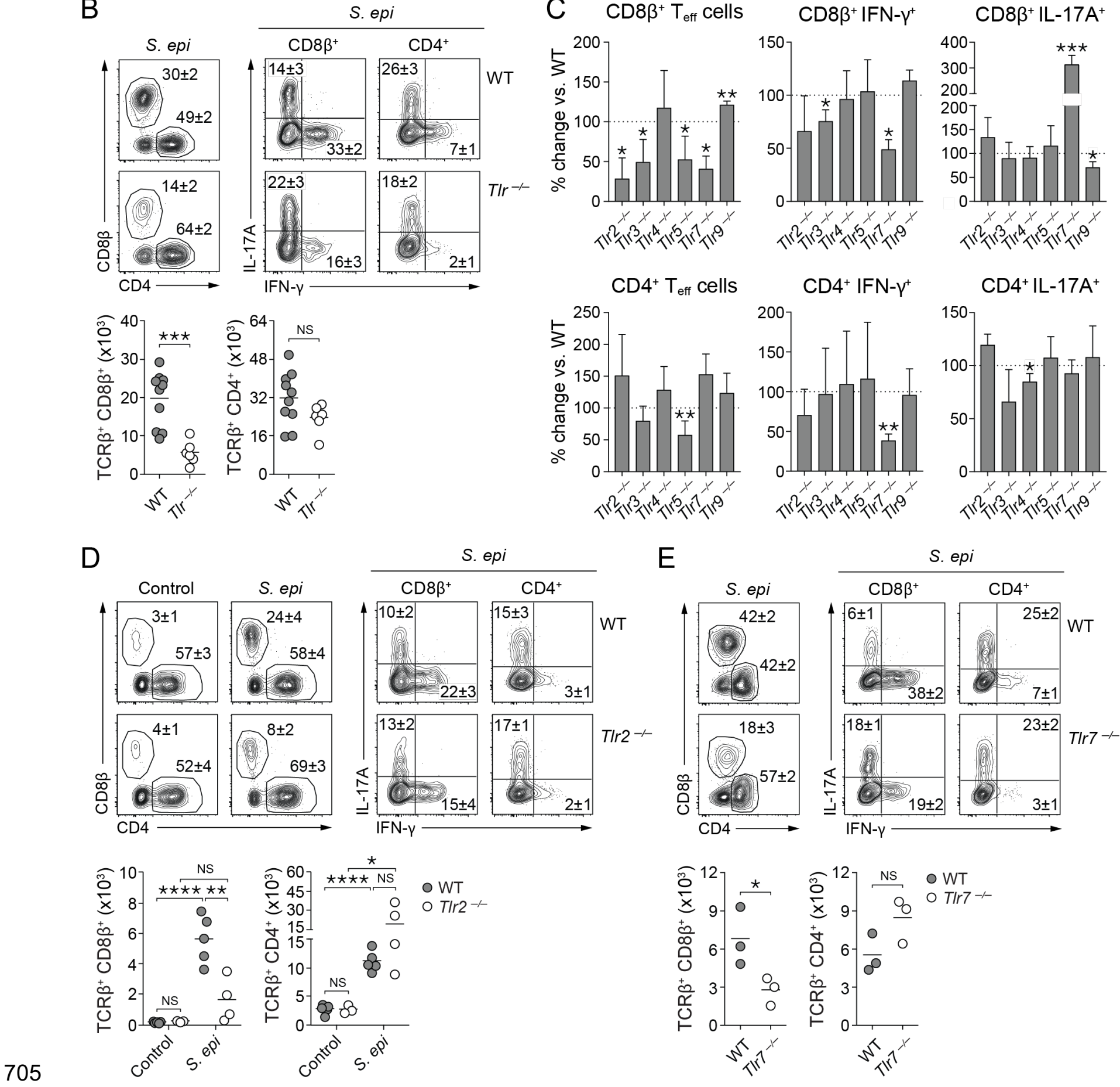
706 Fig. 2. S. epidermidis activation of TLR signaling induces distinct $\mathbf{T}$ cell populations. (A)

707 Experimental schematic of $S$. epidermidis topical association and collection of ears for skin immune 708 phenotyping. (B) Frequencies (top) of total, IFN- $\gamma^{+}$or IL-17A+ CD8 ${ }^{+}$or CD4+ effector T cells in the skin of 709 S. epidermidis-associated wild-type (WT) or complete TLR-deficient ( $\left(\mathrm{r}^{-} /\right)$. Graphs (bottom) represent the 710 absolute numbers of total $\mathrm{CD}^{+}$or $\mathrm{CD}^{+}$effector $\mathrm{T}$ cells where each dot represents data from a single 711 mouse. (C) Percentage change in the numbers of skin CD8 ${ }^{+}$or CD4+ effector T cells and in the frequencies 712 of IL-17A- or IFN- $\gamma$-producing $\mathrm{CD}^{+}$or $\mathrm{CD}^{+}$effector T cells in single TLR knockout mice compared to wild713 type after $S$. epidermidis association. Each bar represents data from at least 4 mice; data from individual 714 mice are shown in Figure S1D-E. (D-E) Frequencies (top) of total, IFN- $\gamma^{+}$or IL-17A+ CD8+ or CD4+ effector 715 T cells in the skin of $S$. epidermidis-associated wild-type (WT), TIr2\% (D), or TIr7\% mice (E). Graphs 716 (bottom) represents the absolute numbers of total CD8+ or CD4+ effector T cells in wild-type (gray circle), 717 TIr2 ${ }^{-/}$(D, white circle), or TIr7\% mice (E, white circle). "Control" denotes wild-type or TIr2 ${ }^{-/}$unassociated 718 mice. For all figures, NS $=$ not significant, ${ }^{*}=p<0.05,{ }^{* *}=p<0.01,{ }^{* *}=p<0.001$, and ${ }^{* * *}=p<0.0001$ in 719 an unpaired, two-tailed t-test. In (B), (D) and (E), flow cytometry plots are gated on live CD45.2 $2^{+}$CD90.2 ${ }^{+}$ $720 \mathrm{TCR}^{+}$Foxp3 cells. Numbers correspond to the frequencies of gated populations \pm SD. Data shown are 721 representative of 2-3 independent experiments. 
A
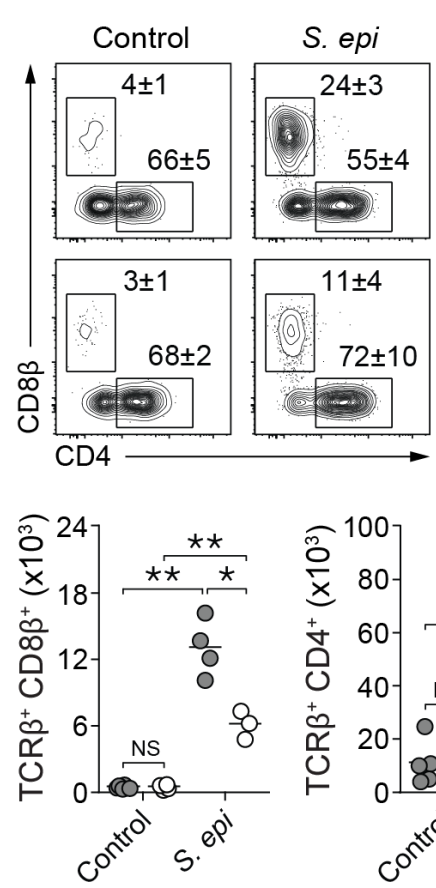

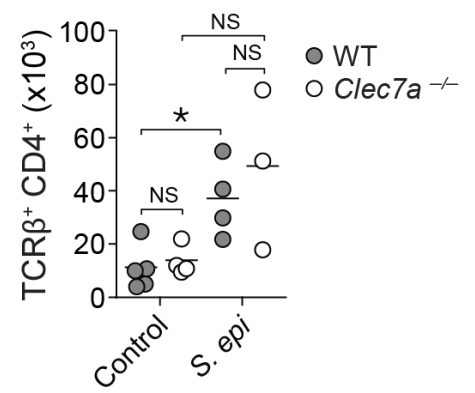

S. epi

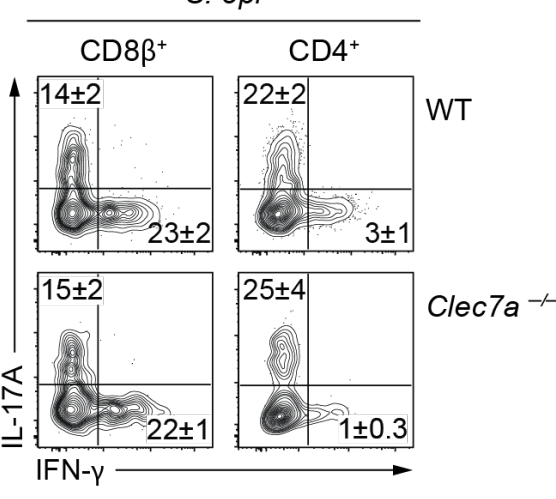

$\mathrm{C}$

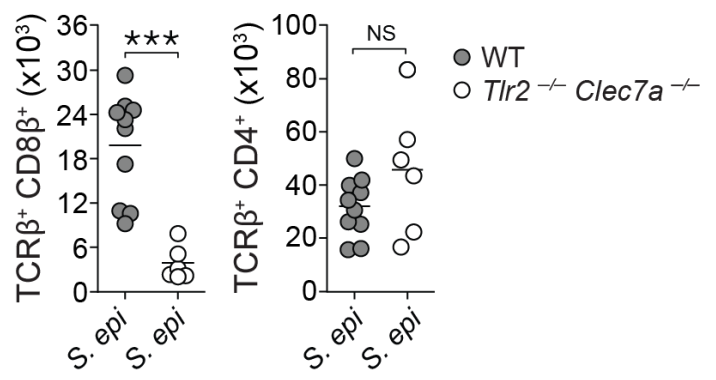

\section{C}

B
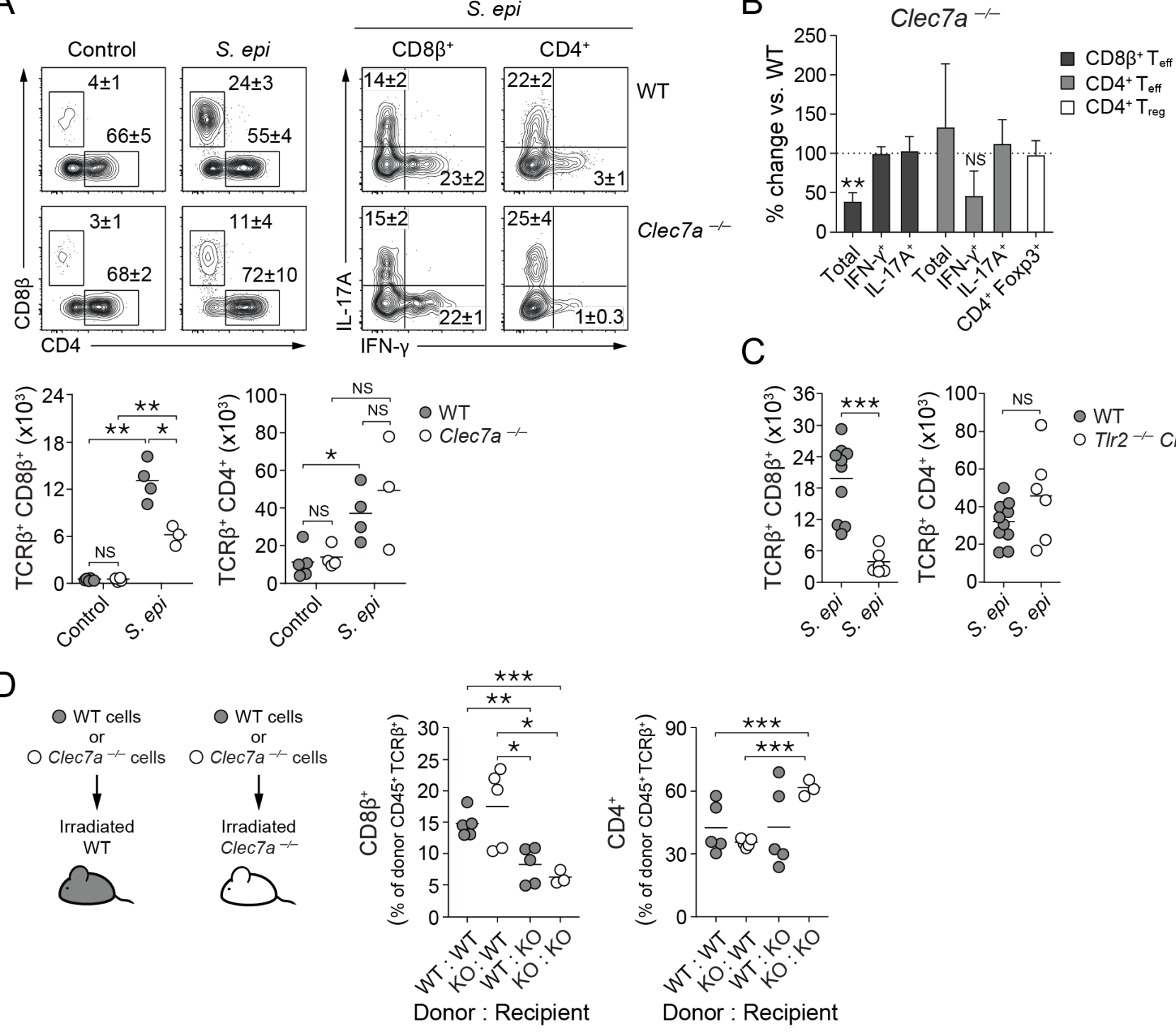

Fig. 3. Sensing of S. epidermidis by Dectin-1 is required for the $C D 8^{+} \mathrm{T}$ cell colonization response. (A) Frequencies (top) of total, IFN- $\gamma^{+}$or $\mathrm{IL}-17 \mathrm{~A}^{+} \mathrm{CD}^{+}$or $\mathrm{CD} 4^{+}$effector $\mathrm{T}$ cells in the skin of wild-type or Clec7a ${ }^{-/-}$mice previously associated with $S$. epidermidis or unassociated (Control). Graphs show the numbers of skin $\mathrm{CD}^{+}$or $\mathrm{CD} 4^{+}$effector T cells in unassociated (Control) or S. epidermidis-associated wildtype (WT, grey circles) or Clec7a-/- mice (white circles) at day 15. Flow cytometry plots are gated on live CD45.2 $2^{+}$CD90.2 $2^{+}$TCR $\beta^{+}$Foxp3- cells and the numbers in flow cytometry plots correspond to the frequencies of gated populations \pm SD. (B) Percentage change of the number of skin total $C D 8^{+}$or $C D 4^{+}$ effector T cells, of the frequencies of IL-17A- or IFN- $\gamma$-producing $\mathrm{CD} 8^{+}$or $\mathrm{CD} 4^{+}$effector T cells, and of the number of regulatory $\mathrm{T}$ cells in Clec7a-/-mice compared to wild-type after $\mathrm{S}$. epidermidis association. Each bar represents data from at least 5 mice. (C) Absolute numbers of skin total $\mathrm{CD} 8^{+}$or $\mathrm{CD} 4^{+}$effector $\mathrm{T}$ cells in S. epidermidis-associated wild-type (grey circles) or T/r2- Clec $7 a^{-/}$double knockout mice (white circles). 
736 (D) Frequencies of skin $\mathrm{CD}^{+}$or $\mathrm{CD}^{+}$effector T cells within the donor hematopoietic cell population in $S$. 737 epidermidis-associated bone marrow chimeric mice with either wild-type donor bone marrow (grey circles) 738 or Clec7a-/- donor bone marrow (white circles). Nomenclature of mice is donor genotype:recipient 739 genotype. Data showing cytokine production by these T cells is in Figure S2D. 
A

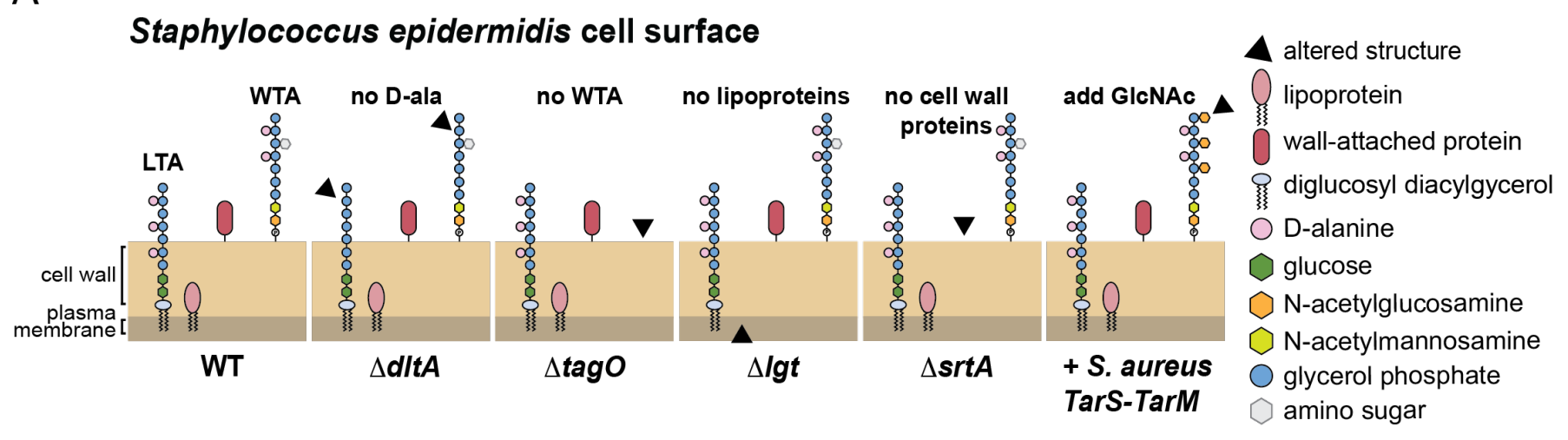

B

C

S. epidermidis
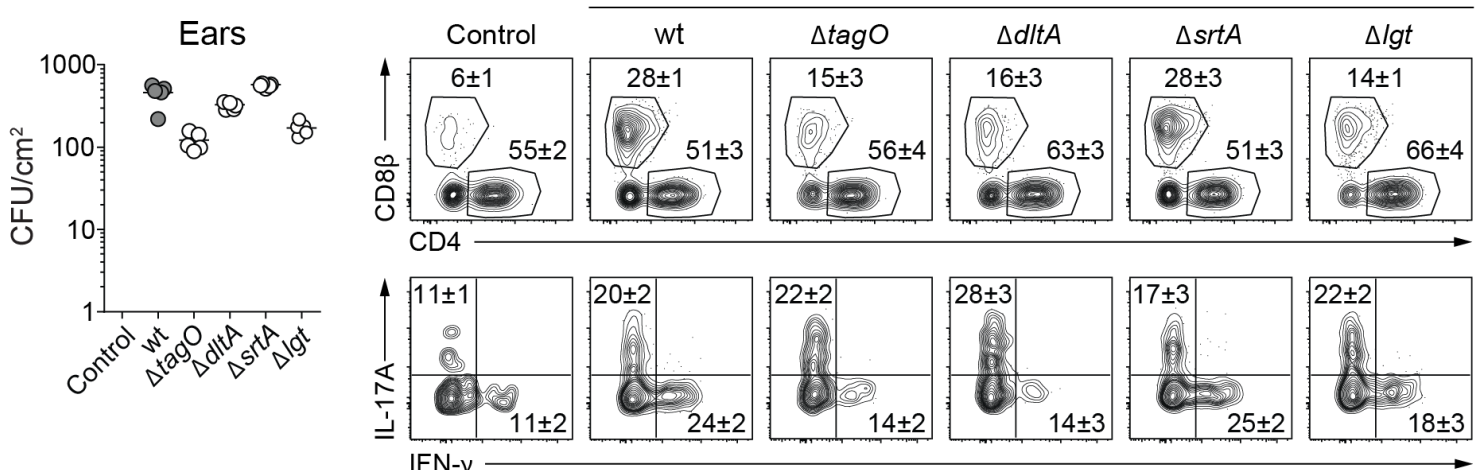

$C D 8 \beta^{+}$

D
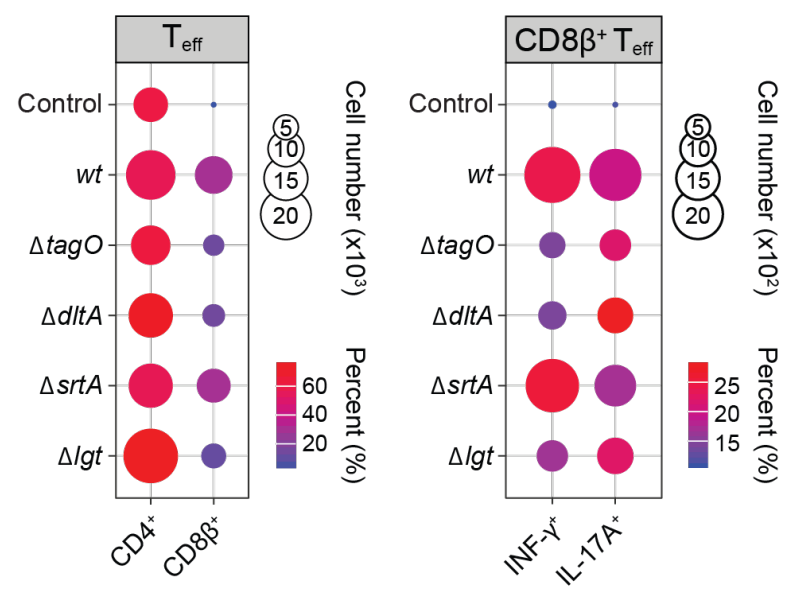

$E$

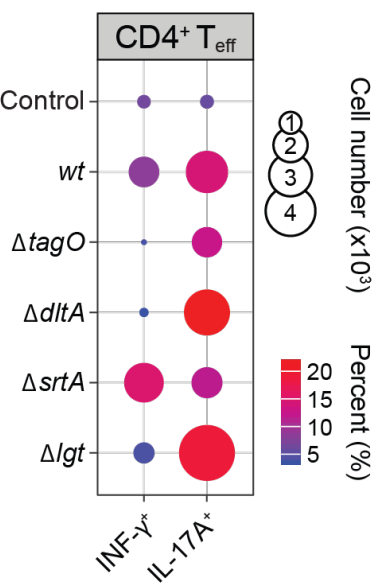

CD4 ${ }^{+} T_{\text {eff }}$ cells
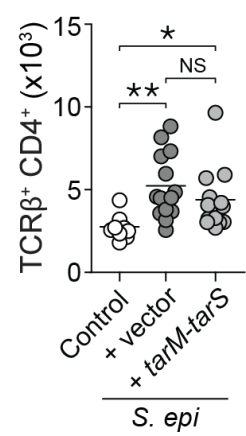
741 Fig. 4. S. epidermidis cell envelope mutants yield distinct patterns of immune cell induction. (A)

742 Schematic showing structural alterations in the cell envelope of $S$. epidermidis mutants. WTA = cell-wall 743 attached wall teichoic acids, LTA = plasma-membrane anchored lipoteichoic acids (LTA). (B) Enumeration 744 of $S$. epidermidis colony-forming units (CFU) isolated from mouse skin on day 14 after application of wild745 type or mutant $S$. epidermidis strains ( $n=4-5$ per group). (C) Frequencies of skin total CD8 ${ }^{+}$and $C D 4^{+}$ 746 effector T cells (top) and IFN- $\gamma$ - or IL-17A-producing CD8+ effector T cells (bottom) in wild-type mice that 747 were unassociated (Control) or associated with wild-type or mutant $S$. epidermidis. Flow plots are gated 748 live CD45.2 $2^{+}$CD90.2+ TCR $\beta^{+}$Foxp3 cells and the numbers in flow cytometry plots correspond to the 749 frequencies of gated populations \pm SD. (D) Mean of absolute numbers (represented by circle size) and 750 frequencies (represented by the circle color) of total, IFN- $\gamma^{+}$or IL-17A+ CD8 ${ }^{+}$or CD4+ effector T cells isolated 751 from the skin of mice that were unassociated (Control) or associated with wild-type or mutant S. epidermidis 752 strains. Data is aggregated from at least 4 mice per group and representative of multiple experimental 753 replicates. Raw data is in Figure S4. (E) Absolute numbers of total CD4+ effector T cells and of total, IFN$754 \gamma^{+}$or IL-17A+ CD8+ effector T cells in wild-type mice that were unassociated (Control) or associated with $S$. 755 epidermidis containing empty vector pLI50 (+vector) or S. epidermidis expressing S. aureus TarM and 756 TarS on pLI50 (+tarM-tarS). 
A

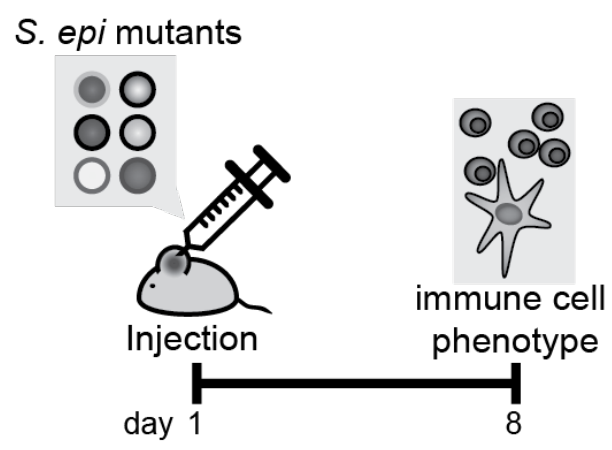

B

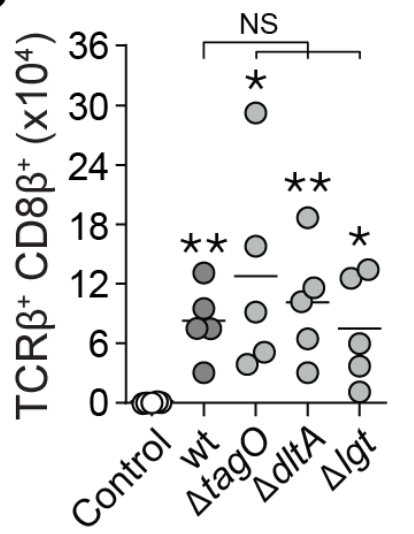

759

760

761

762

763

764

765

766

767

768

769
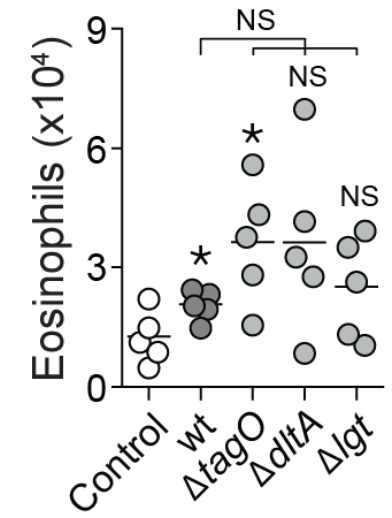

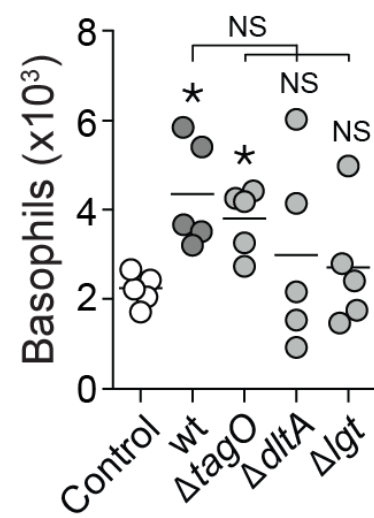

C
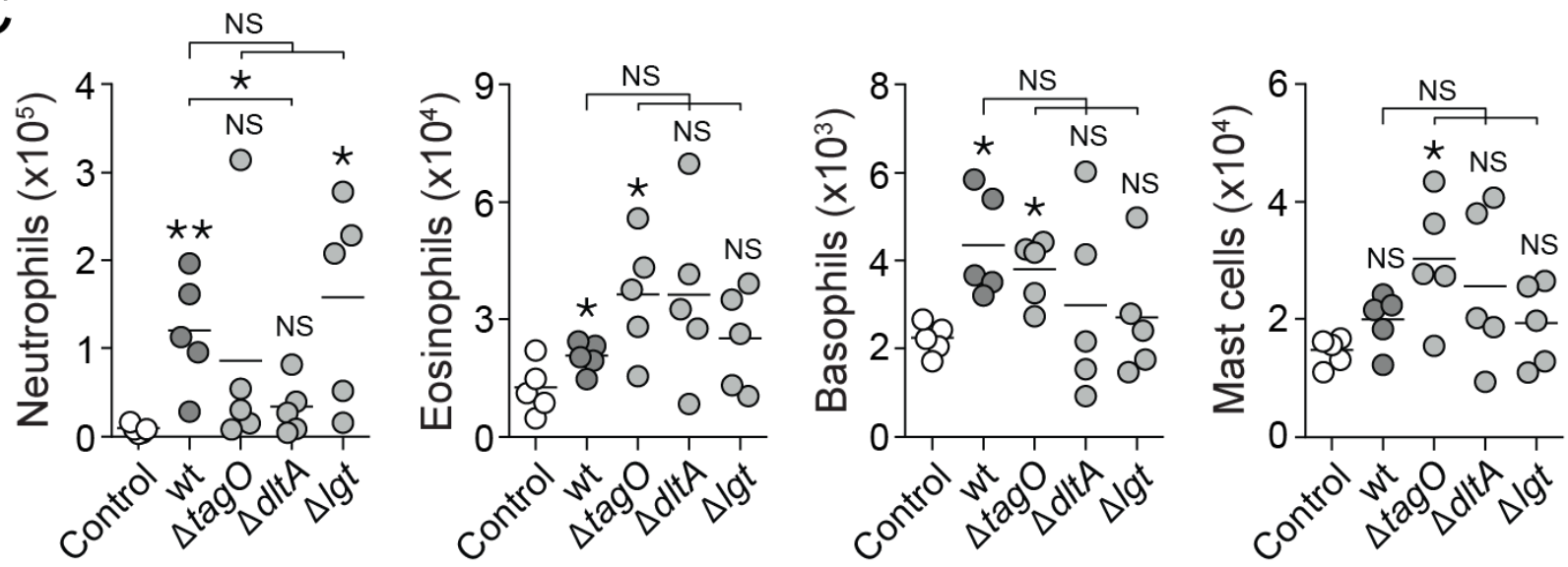

Fig. 5. S. epidermidis cell envelope mutations alter the innate inflammatory response but not the $T$ cell response in an infection model. (A) Experimental schematic of infection model where $S$. epidermidis is injected intradermally into the ear on day 1 and immune phenotyping of the skin occurs on day 8. (B) Absolute numbers of $\mathrm{CD}^{+}$and $\mathrm{CD} 4^{+}$effector $\mathrm{T}$ cells after intradermal injection of wild-type or mutant $S$. epidermidis. (C) Absolute numbers of innate immune populations in unassociated mice (Control, white circles) or 1 week after intradermal injection of wild-type (wt, dark grey circles) or mutant (light grey circles) S. epidermidis. Gating strategy for innate cell populations is shown in Figure S4. For all figures, each dot represents a single mouse. NS $=$ not significant, ${ }^{*}=p<0.05$ and ${ }^{* *}=p<0.01$ in an unpaired, two-tailed ttest. Asterisks directly above each set of data points denotes comparison to the unassociated mice (Control, white circles). Data shown are representative of 2 independent experiments. 


\section{Figure S1}

A

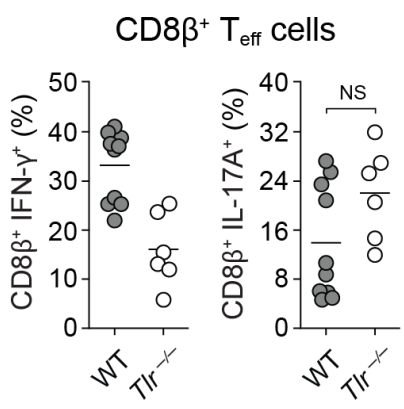

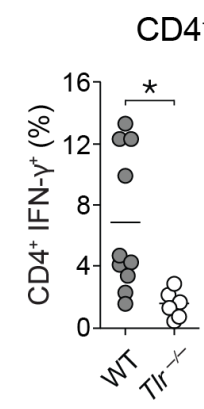

$\mathrm{CD} 4^{+} \mathrm{T}_{\text {eff }}$ cells

C
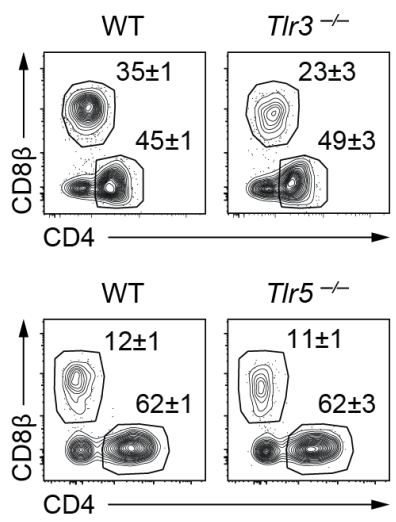

$\mathrm{D}$
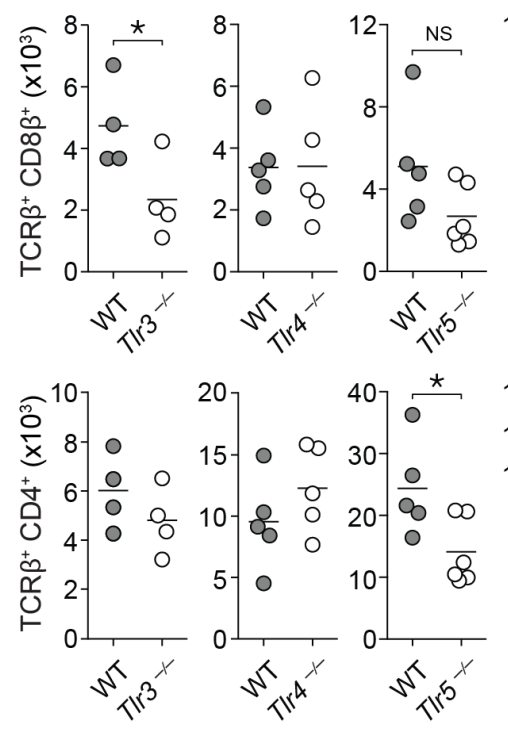
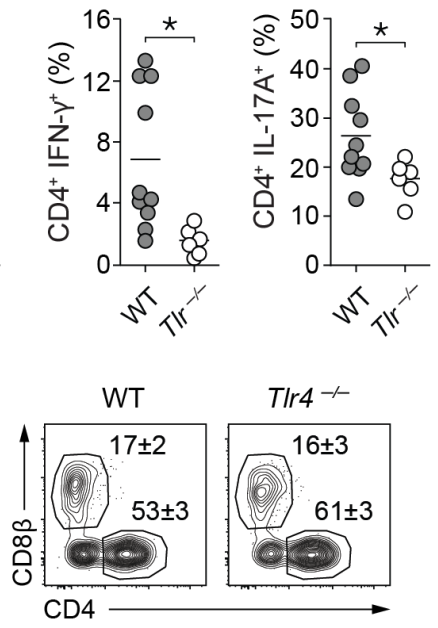

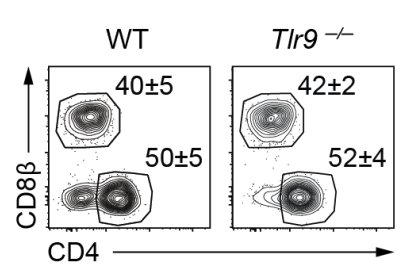

$E$
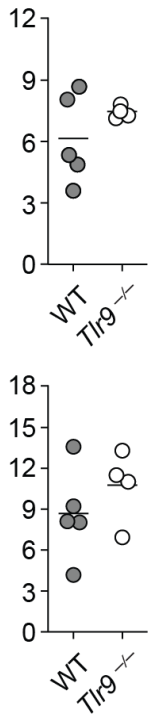

$\mathrm{B}$

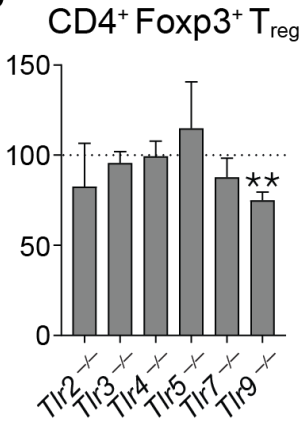

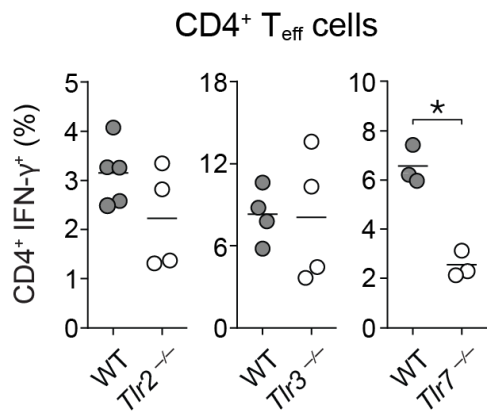

Fig. S1. Topical association of S. epidermidis in TLR knockout mice. (A) Frequencies of skin IL-17A-
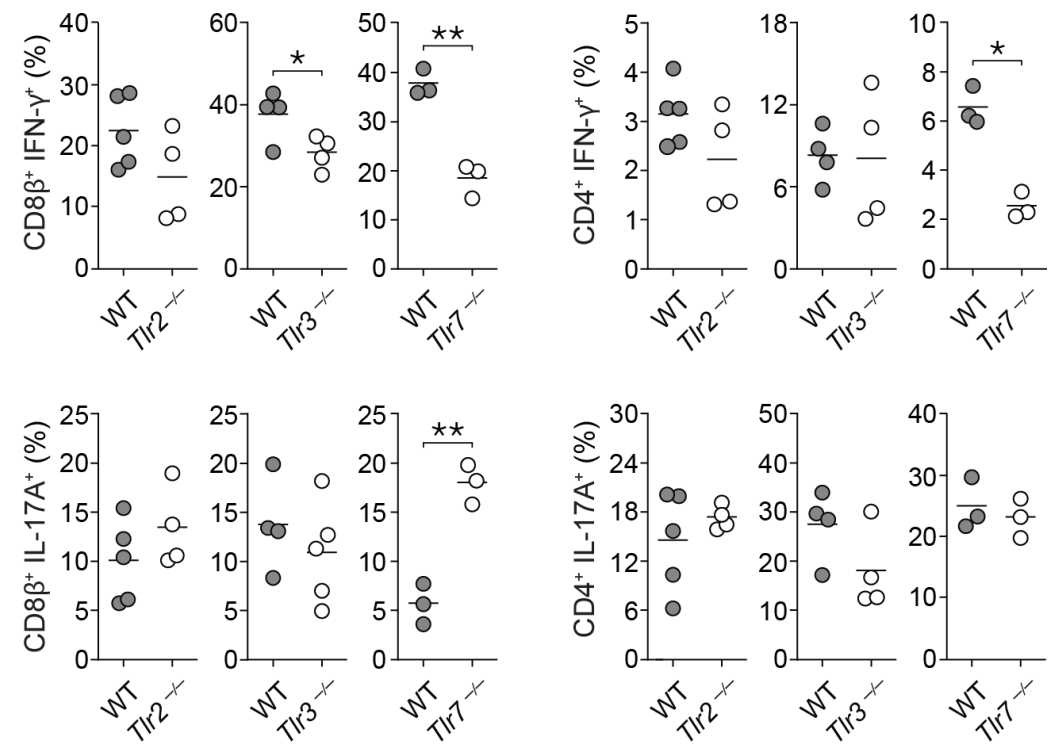
or IFN- $\gamma$-producing CD8+ or CD4+ effector T cells in wild-type (WT) or complete TLR knockout (T/r/) mice

775 in Figure 1B. (B) Percentage change of the frequencies of skin regulatory T cells (TCR $\beta^{+} \mathrm{CD} 4^{+}$Foxp3 $3^{+}$) in 776 various single TLR knockout mice compared to wild-type after $S$. epidermidis association. Each bar 
777 represents data from at least 4 mice. For panels (C)-(E): Raw data showing (C) frequencies of skin total $778 \mathrm{CD}^{+}$and CD4 ${ }^{+}$effectorT cells, (D) absolute numbers of skin total CD8 ${ }^{+}$and CD4+ effector T cells, and (E) 779 frequencies of IFN- $\gamma$ - or IL-17A-producing $\mathrm{CD}^{+}$or $\mathrm{CD}^{+}{ }^{+}$effector T cells in various single TLR knockout 780 mice after $S$. epidermidis association. In panel C, flow cytometry plots are gated on live CD45.2+ CD90.2+ $781 \mathrm{TCR} \beta^{+}$Foxp3 cells and the numbers in flow cytometry plots correspond to the frequencies of gated 782 populations \pm SD. Panels $(B-E)$ represents additional data from the same experiment shown in Figure 1C783 E. For all figures, each dot represents a single mouse. NS = not significant, ${ }^{*}=p<0.05$ and ${ }^{\star \star}=p<0.01$ in 784 an unpaired, two-tailed t-test.

785

786 


\section{Figure S2}

A
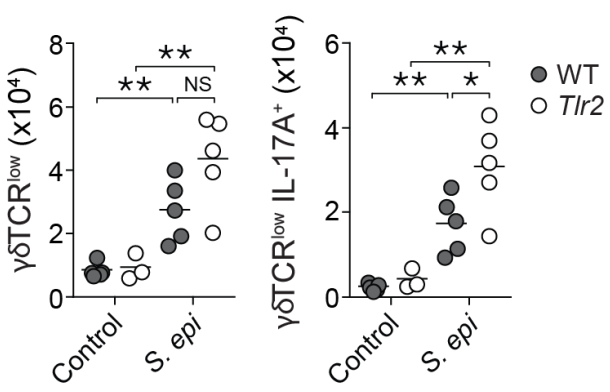

C

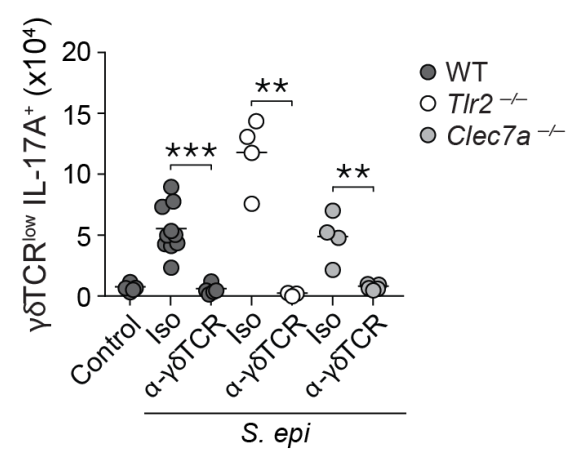

$E$
Donor : Recipient sito $5<0$
B

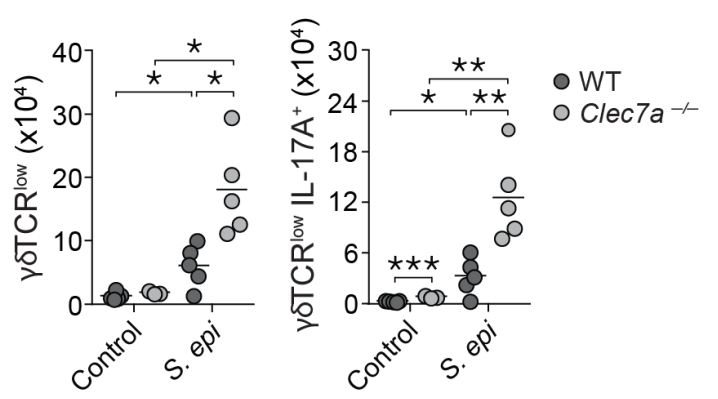

D

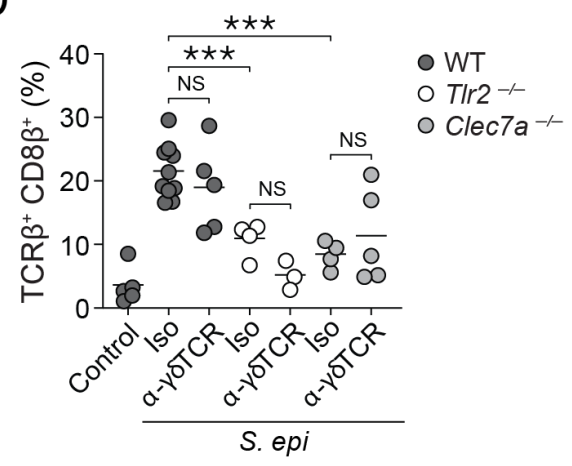

$$
\mathrm{CD}^{+} \mathrm{T}_{\text {eff }} \text { cells }
$$

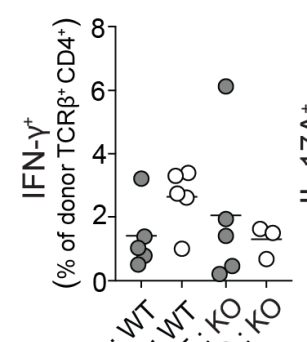

anio

Donor : Recipient

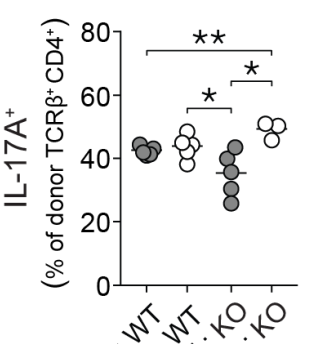

sin $5>0$

Donor : Recipient

Fig. S2. The skin $\mathrm{CD}^{+}$and $\mathrm{CD} 4^{+} \mathrm{T}$ cell response to $S$. epidermidis association is independent of $\gamma \delta-$ T cells. (A-B) Absolute numbers of live $\mathrm{CD} 45^{+} \mathrm{CD} 90.2^{+} \gamma \delta \mathrm{TCR}^{\text {low }} \mathrm{T}$ cells in unassociated (Control) or $S$. epidermidis-associated (S. epI) wild-type mice (WT, grey circles), TIr2-- mice (white circles), or Clec7a- ${ }^{-1}$ mice (light grey circles). (C-D) Wild-type (WT), TIr2/-, or Clec7a-/- mice were associated with S. epidermidis and treated with an isotype control antibody or an anti- $\gamma \delta \mathrm{TCR}$ antibody. Control animals were untreated and unassociated. (C) Absolute numbers of live CD45+ ${ }^{+} D 90.2^{+} \gamma \delta \mathrm{TCR}^{\text {low }} \mathrm{T}$ cells producing IL-17A and (D) frequencies of total CD8 $8^{+}$effector T cells in the skin of wild-type (dark circles), TIr2/- (white circles) or $\mathrm{Clec}^{-1-}$ mice (light grey circles). Panels C-D show data from the same experiment. (E) Frequencies of skin IFN- $\gamma$-producing or IL-17A-producing $\mathrm{CD}^{+}$or $\mathrm{CD}^{+}$effector $\mathrm{T}$ cells within the donor hematopoietic cell population in $S$. epidermidis-associated bone marrow chimeric mice with either wild-type donor bone 
799 marrow (grey circles) or clec7a-/- donor bone marrow (white circles). Nomenclature of mice is donor 800 genotype:recipient genotype. These are additional data from the same experiment shown in Figure 3D. $801 \mathrm{NS}=$ not significant, ${ }^{*}=\mathrm{p}<0.05,{ }^{* *}=\mathrm{p}<0.01$ and ${ }^{* *}=\mathrm{p}<0.001$ in an unpaired, two-tailed t-test. 


\section{Figure S3}
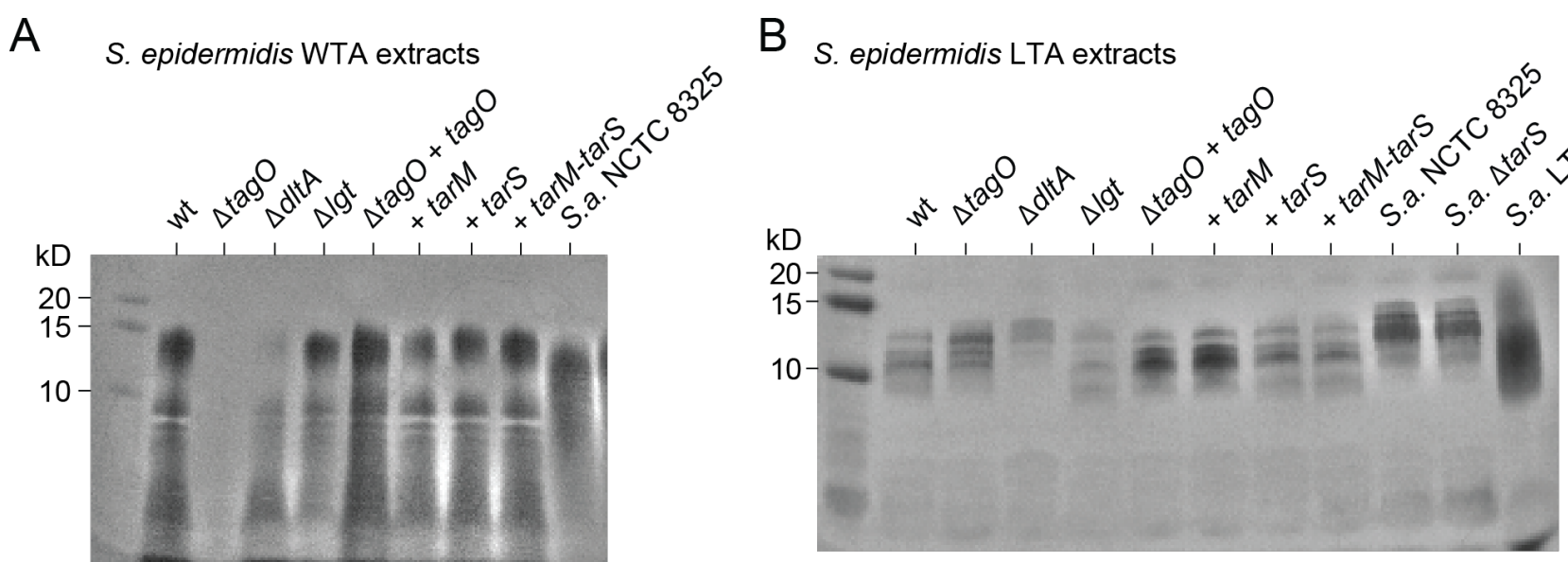

C

S. epidermidis

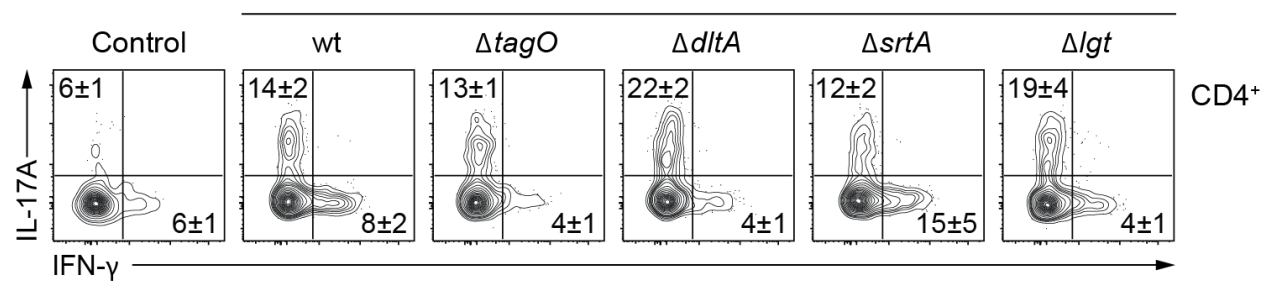

$\mathrm{D}$

CFU/cm² vs CD8 $\beta^{+} \mathrm{T}_{\text {eff }}$ cells

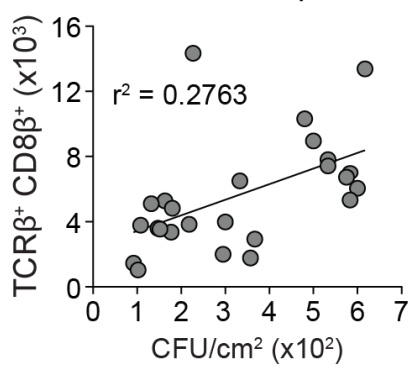

$\mathrm{CFU} / \mathrm{cm}^{2}$ vs CD4 ${ }^{+} \mathrm{T}_{\text {eff }}$ cells

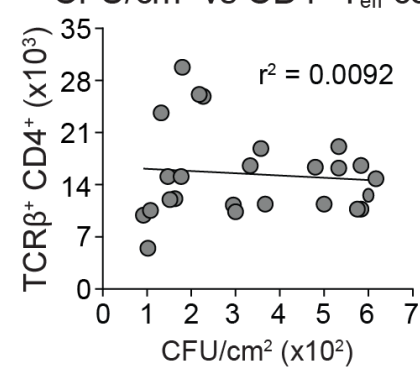

E
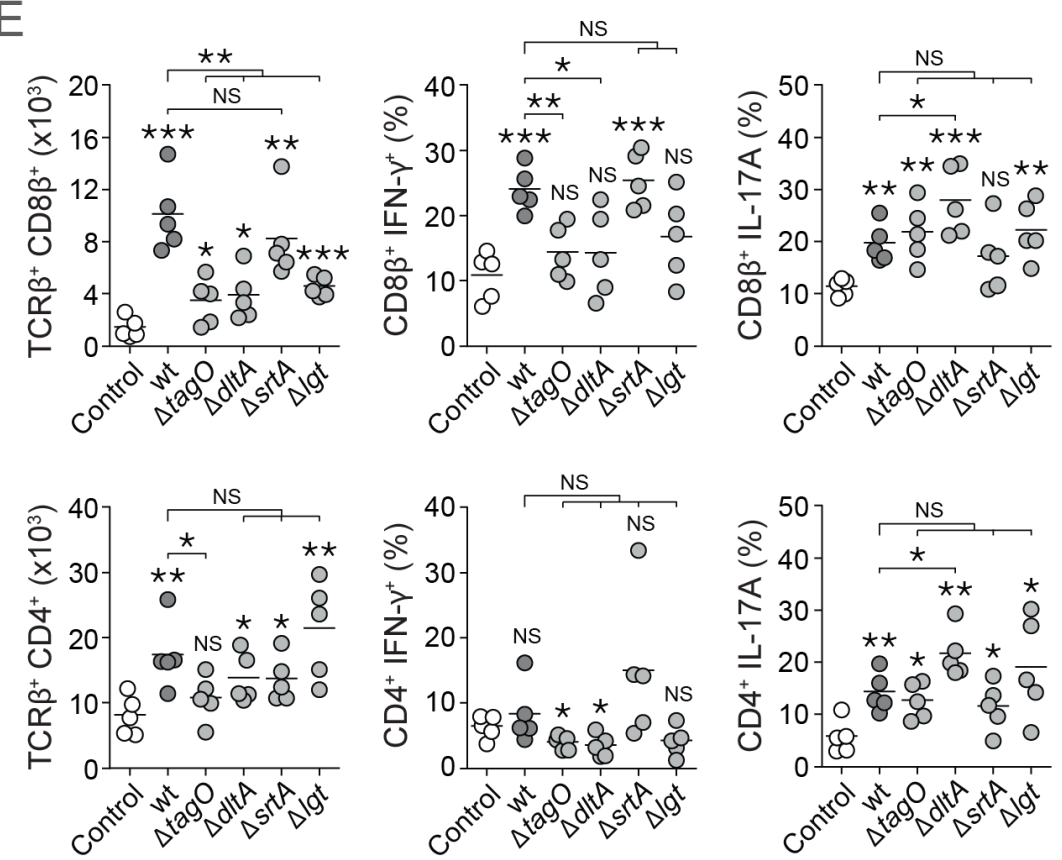

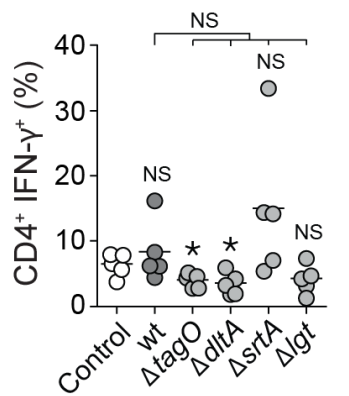

Fig. S3. Characterization of S. epidermidis mutants. (A) Alcian blue-silver stain of wall teichoic acid extracts from S. epidermidis mutants or $S$. aureus strain NCTC8325 using the acid hydrolysis method (Shiratsuchi et al., 2010). As expected $\Delta$ tagO does not produce wall teichoic acid. (B) Alcian blue-silver stain of lipoteichoic acid, extracted as previously described (Gründling and Schneewind, 2007). The last 
$810 \mathrm{IL}^{-17 \mathrm{~A}^{+}}$or IFN- $\gamma^{+} \mathrm{CD} 4^{+} \mathrm{T}$ cells in wild-type mice that were unassociated (Control) or associated with live 811 wild-type or mutant S. epidermidis. Flow plots are gated live CD45.2+ CD90.2+ TCR $\beta^{+}$CD4+ Foxp3- cells 812 and the numbers in flow cytometry plots correspond to the frequencies of gated populations \pm SD. These 813 are additional data from the same experiment shown in Figure 4C. (D) S. epidermidis colonization does 814 not correlate significantly to $\mathrm{CD}^{+}$or $\mathrm{CD} 4^{+} \mathrm{T}$ cell stimulation. Each dot represents data from one mouse, 815 showing the $\mathrm{T}$ cell response on the $\mathrm{Y}$-axis and the number of $\mathrm{S}$. epidermidis $\mathrm{CFU} / \mathrm{cm}^{2}$ recovered by plating 816 from mouse skin swabs at the time of immune phenotyping on the X-axis. (E) Absolute numbers of total $817 \mathrm{CD}^{+}$and CD4+ effector T cells and frequencies of IFN- $\gamma-$, or IL-17A-producing CD8 ${ }^{+}$or CD4+ effector T 818 cells in wild-type mice that were unassociated (Control) or associated with live wild-type or mutant $S$. 819 epidermidis. Each dot represents data from one mouse. NS = not significant, ${ }^{*}=p<0.05,{ }^{* *}=p<0.01$ and $820^{* * *}=\mathrm{p}<0.001$ in an unpaired, two-tailed t-test. Asterisks directly above each set of data points denotes 821 comparison to the unassociated mice (Control, white circles). Data shown are representative of 3 822 independent experiments. These are the data used to generate Figure 4D. 


\section{Figure S4}
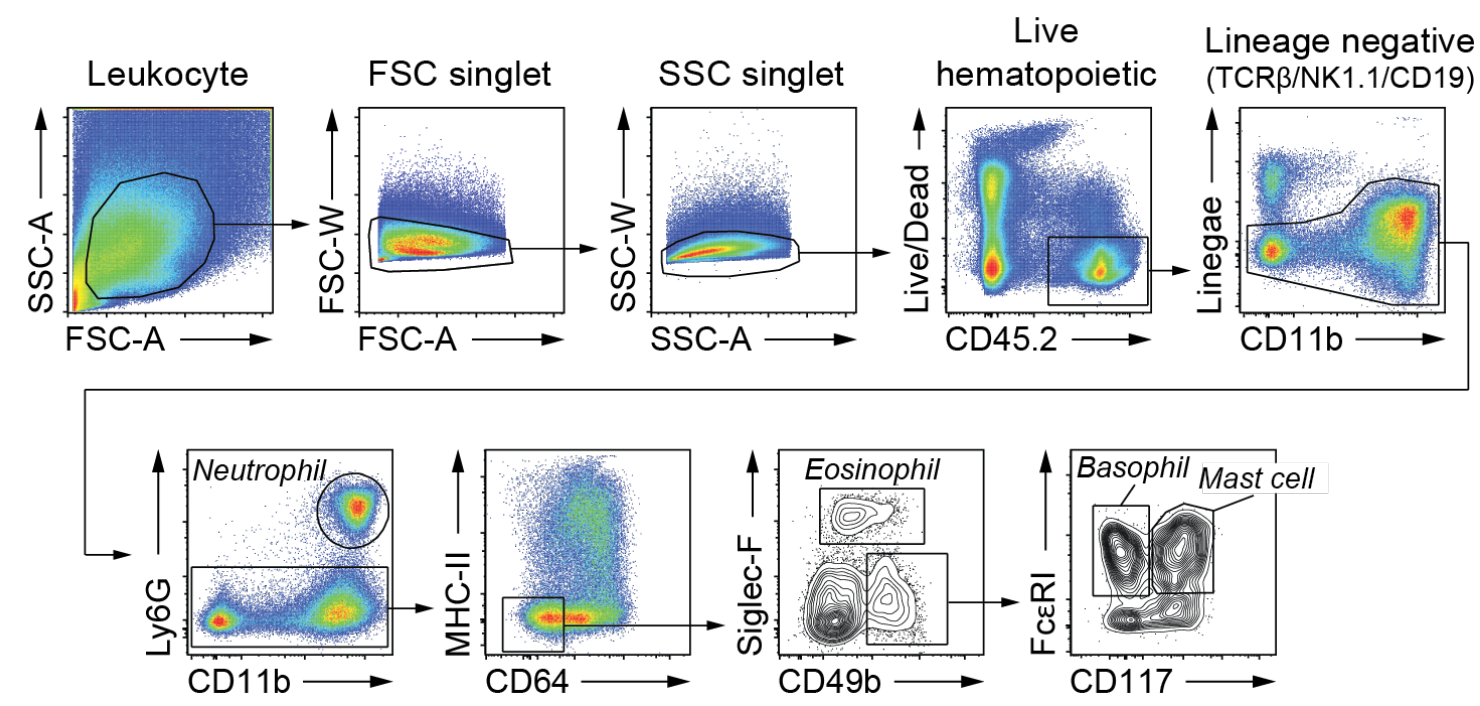

826 data shown in Figure 5C. 


\section{Figure S5}
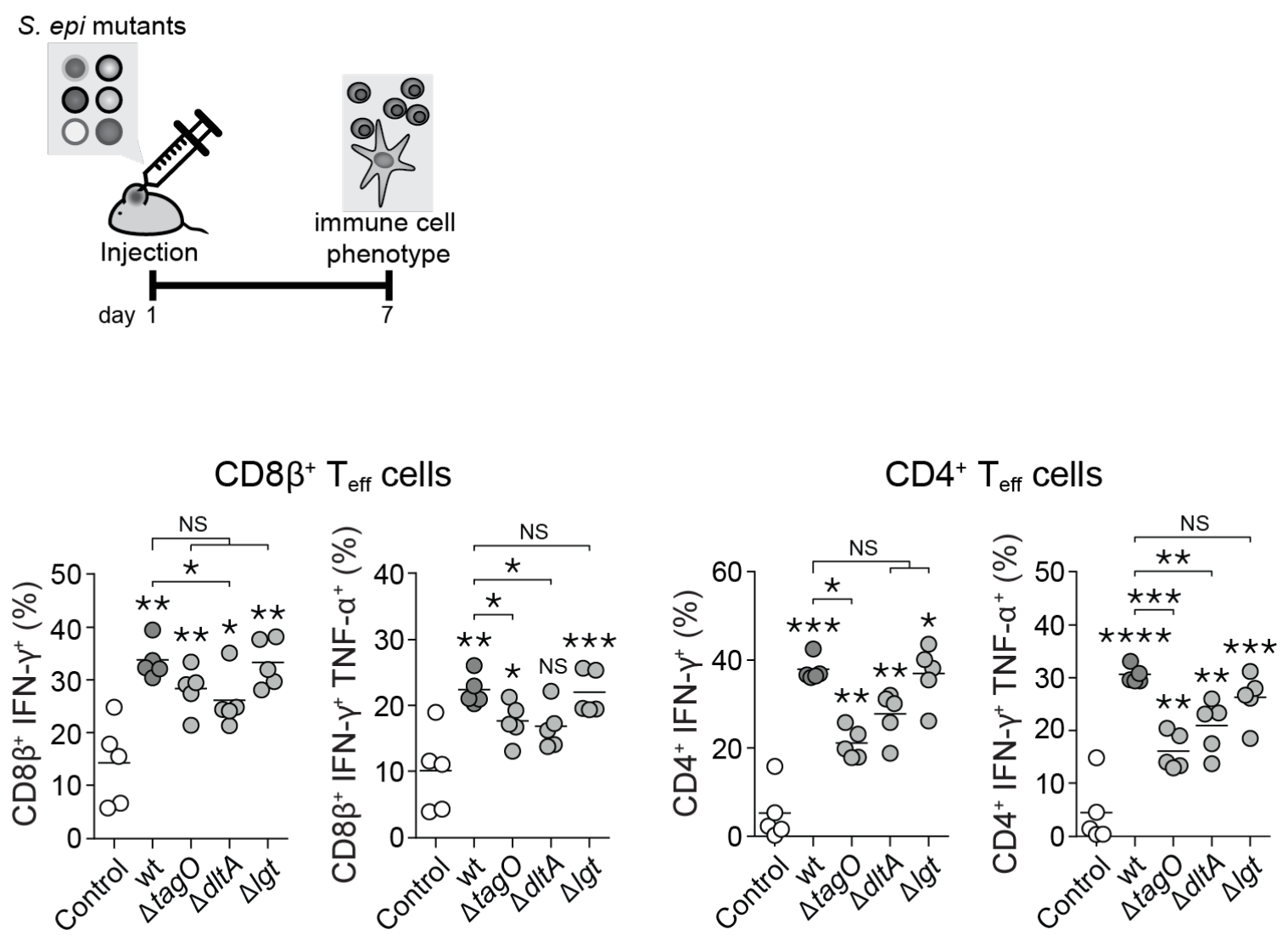

Fig. S5. Cytokine production by $\mathrm{T}$ cells in response to intradermal injection of wild-type or mutant

S. epidermidis. Frequencies of IFN- $\gamma^{+}$or IFN- $\gamma^{+} \mathrm{TNF}-\alpha^{+} \mathrm{CD} 8^{+}$and $\mathrm{CD} 4^{+}$effector $\mathrm{T}$ cells 1 week after intradermal injection of wild-type or mutant $S$. epidermidis. Each dot represents data from one mouse. NS $=$ not significant, ${ }^{*}=\mathrm{p}<0.05,{ }^{* *}=\mathrm{p}<0.01,{ }^{* * *}=\mathrm{p}<0.001$ and ${ }^{* * *}=\mathrm{p}<0.0001$ in an unpaired, two-tailed $\mathrm{t}-$ test. Asterisks directly above each set of data points denotes comparison to the unassociated mice (Control, white circles). These are additional data from the same experiment as Figure 5. 
Table S1

\begin{tabular}{|c|c|c|c|c|c|c|c|}
\hline $\begin{array}{l}\text { Gene } \\
\text { name }\end{array}$ & $\begin{array}{l}\text { S. aureus } \\
\text { NCTC8325 } \\
\text { locus ID }\end{array}$ & $\begin{array}{l}\text { Closest S. } \\
\text { epidermidis LM087 } \\
\text { homolog locus ID }\end{array}$ & $\begin{array}{c}\text { Protein } \\
\text { Blast } \\
\text { identity } \\
(\%)\end{array}$ & $\begin{array}{c}\text { Protein } \\
\text { Blast } \\
\text { Query } \\
\text { coverage } \\
\text { (\%) }\end{array}$ & $\begin{array}{l}\text { Predicted } \\
\text { functional } \\
\text { homolog? }\end{array}$ & Known function in $S$. aureus & S. aureus reference \\
\hline \multicolumn{8}{|c|}{ Well-conserved genes } \\
\hline $\operatorname{tag} \mathrm{O}$ & SAOUHSC_00762 & HMPREF9993_01487 & 80.63 & 100 & yes & Initiate wall teichoic acid synthesis & $\begin{array}{l}\text { (Soldo et al., 2002; } \\
\text { Weidenmaier et al., 2004) }\end{array}$ \\
\hline Itas & SAOUHSC_00728 & HMPREF9993_01652 & 87.77 & 100 & yes & Lipoteichoic acid polymerase & $\begin{array}{l}\text { (Gründling and Schneewind, } \\
\text { 2006; Oku et al., 2009) }\end{array}$ \\
\hline dlttA & SAOUHSC_00869 & HMPREF9993_01022 & 76.91 & 100 & yes & Initiates D-ala addition to teichoic acids & $\begin{array}{l}\text { (Heaton and Neuhaus, } \\
\text { 1994; Peschel et al., 1999) }\end{array}$ \\
\hline lgt & SAOUHSC_00782 & HMPREF9993_01417 & 67.03 & 100 & yes & Essential for lipoprotein synthesis & (Stoll et al., 2005) \\
\hline sitA & SAOUHSC_02834 & HMPREF9993_05483 & 72.2 & 99 & yes & Sortase - attaches proteins to the cell wall & (Mazmanian et al., 2000) \\
\hline yfhO & SAOUHSC_01213 & HMPREF9993_02799 & 53.58 & 96 & likely & Adds a-O-GICNAc to lipoteichoic acid & (Kho and Meredith, 2018) \\
\hline \multicolumn{8}{|c|}{ Divergent genes } \\
\hline \multirow[t]{4}{*}{$\operatorname{tarM}$} & DQM91_RS04830 & HMPREF9993_05648 & 27.01 & 92 & no & Adds a-O-GIcNAc to wall teichoic acid & (Xia et al., 2010) \\
\hline & & HMPREF9993_04889 & 24.38 & 99 & no & & \\
\hline & & HMPREF9993_05249 & 24.72 & 86 & no & & \\
\hline & & HMPREF9993_01968 & 24.19 & 70 & no & & \\
\hline \multirow[t]{2}{*}{$\operatorname{tars}$} & SAOUHSC_00228 & $\begin{array}{l}\begin{array}{l}\text { HMPREF9993_06098 } \\
(\operatorname{tag} F)\end{array} \\
\end{array}$ & 26.48 & 35 & no & Adds b-O-GIcNAc to wall teichoic acid & (Sobhanifar et al., 2016) \\
\hline & & HMPREF9993_11963 & 30.87 & 24 & no & & \\
\hline
\end{tabular}

\section{Table S1 references}

Gründling, A., and Schneewind, O. (2006). Cross-Linked Peptidoglycan Mediates Lysostaphin Binding to

840 Heaton, M.P., and Neuhaus, F.C. (1994). Role of the D-alanyl carrier protein in the biosynthesis of D841 alanyl-lipoteichoic acid. J. Bacteriol. 176, 681-690.

842 Kho, K., and Meredith, T.C. (2018). Salt-Induced Stress Stimulates a Lipoteichoic Acid-Specific Three843 Component Glycosylation System in Staphylococcus aureus. J. Bacteriol. 200, e00017-18. sortase mutants defective in the display of surface proteins and in the pathogenesis of animal infections. Proc. Natl. Acad. Sci. U. S. A. 97, 5510-5515. Operon inStaphylococcus aureus Confers Sensitivity to Defensins, Protegrins, and Other Antimicrobial Peptides. J. Biol. Chem. 274, 8405-8410. e1006067. 
859 Stoll, H., Dengjel, J., Nerz, C., and Götz, F. (2005). Staphylococcus aureus Deficient in Lipidation of 860 Prelipoproteins Is Attenuated in Growth and Immune Activation. Infect. Immun. 73, 2411-2423.

861 Weidenmaier, C., Kokai-Kun, J.F., Kristian, S.A., Chanturiya, T., Kalbacher, H., Gross, M., Nicholson, G., 862 Neumeister, B., Mond, J.J., and Peschel, A. (2004). Role of teichoic acids in Staphylococcus aureus 863 nasal colonization, a major risk factor in nosocomial infections. Nat. Med. 10, 243.

864 Xia, G., Maier, L., Sanchez-Carballo, P., Li, M., Otto, M., Holst, O., and Peschel, A. (2010). Glycosylation 865 of wall teichoic acid in Staphylococcus aureus by TarM. J. Biol. Chem. jbc.M109.096172. 